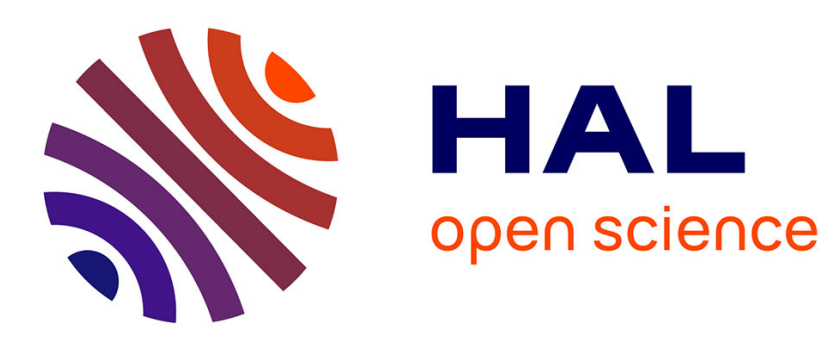

\title{
Hadley circulation changes under global warming conditions indicated by coupled climate models
}

\author{
Guillaume Gastineau, Hervé Le Treut, Laurent Li
}

\section{To cite this version:}

Guillaume Gastineau, Hervé Le Treut, Laurent Li. Hadley circulation changes under global warming conditions indicated by coupled climate models. Tellus A, 2008, 60 (5), pp.863-884. 10.1111/j.16000870.2008.00344.x . hal-01332182

\section{HAL Id: hal-01332182 \\ https://hal.sorbonne-universite.fr/hal-01332182}

Submitted on 15 Jun 2016

HAL is a multi-disciplinary open access archive for the deposit and dissemination of scientific research documents, whether they are published or not. The documents may come from teaching and research institutions in France or abroad, or from public or private research centers.
L'archive ouverte pluridisciplinaire HAL, est destinée au dépôt et à la diffusion de documents scientifiques de niveau recherche, publiés ou non, émanant des établissements d'enseignement et de recherche français ou étrangers, des laboratoires publics ou privés. 


\title{
Hadley circulation changes under global warming conditions indicated by coupled climate models
}

\author{
By GUILLAUME GASTINEAU ${ }^{1,2 *}$, HERVÉ LE TREUT ${ }^{1}$ and LAURENT LI ${ }^{1},{ }^{1}$ Laboratoire de \\ Météorologie Dynamique, Université Pierre et Marie Curie-Paris6/CNRS, Paris, France; ${ }^{2}$ Rosenstiel School for \\ Marine and Atmospheric Science, University of Miami, Miami, FL, USA
}

(Manuscript received 11 October 2007; in final form 19 May 2008)

\begin{abstract}
We use the mean meridional tropical circulation of the Atmospheric Ocean Coupled General Circulation Models (AOGCM) to diagnose and quantify the modifications of the mean meridional circulation of the atmosphere under global warming conditions. The AOGCMs generally show a weakening of the Hadley circulation for the winter cell in both hemispheres, accompanied by a poleward extension of the Hadley circulation area. The conditions explaining these modifications are analysed using detailed outputs from IPSL-CM4. The AOGCM IPSL-CM4 shows changes, under $\mathrm{CO}_{2}$ doubling, that are in accordance with the other models, for austral winter. On the other hand, for boreal winter, the winter cell shows little change in intensity and in extension. The poleward shift of the Southern Hemisphere winter Hadley cell corresponds to changes in the transient eddies, whereas the increase of the dry static stability is mainly responsible for the mean weakening of the cell. For boreal winter, a strong shrinking of the ascending branch area, and an increase of the latent heating, is found to cancel the weakening of the circulation due to dry static stability increase.
\end{abstract}

\section{Introduction}

The large-scale atmospheric circulation in the tropics constitutes a key element of the tropical climate. Its coupling with processes in relation to atmospheric radiation, the boundary layer and clouds is believed to play a major role in determining the basic state of the tropical climate (Betts and Ridgway, 1988) and in modulating transient systems, such as the tropical cyclones or squall lines, which have strong societal impacts. It is important to understand the mechanisms controlling the tropical atmospheric circulation and its variation under global warming context.

At the same time, the tropical large-scale atmospheric circulation also has a strong effect on the sensitivity of the global climate system to a radiative perturbation. This was clearly demonstrated through simple models of the tropics (Pierrehumbert, 1995; Larson et al., 1999), although the effect is difficult to diagnose in more complex models due to feedbacks from other processes (Clement and Soden, 2005).

By analysing results of atmospheric GCMs, Knutson and Manabe (1995), Sugi et al. (2002) showed that the tropical atmospheric circulation may weaken in response to increased

\footnotetext{
${ }^{*}$ Corresponding author. e-mail: gglmd@lmd.jussieu.fr DOI: $10.1111 /$ j.1600-0870.2008.00344.x
}

greenhouse gases. They showed that in the subsiding regions, the increase in the dry static stability is stronger than that of the radiative cooling, which leads to a weakening of the tropical circulation. Held and Soden (2006) also reached the conclusion of a weakening tropical circulation under global warming, they found that the water vapour concentration closely follows the Clausius-Clapeyron equation, whereas the precipitation increases more slowly implying a weakening of the atmospheric mass circulation. Further studies conducted by Vecchi et al. (2006) and Vecchi and Soden (2007), using either observed data of the 20th-century or future IPCC scenarios, also identified a weakening of the tropical circulation, which is particularly visible in its longitudinal component, that is, the Walker circulation.

The tropical meridional circulation, that is, the Hadley circulation is also expected to decrease under global warming. Recent studies support these results. Mitas and Clement (2006) examined the Hadley circulation of the 20th century AR4 simulations, and showed a modest decrease of the Northern Hemisphere wintertime (DJF) streamfunction. They explained it by the increase of the static stability in the GCMs. Furthermore, Lu et al. (2007) also diagnosed a weakening of the Hadley circulation in the scenario simulation of global warming, which is in the order of $\sim 1 \%$ per $\mathrm{K}$ of surface warming.

The intensity of the Hadley cell circulation is not the only important parameter; the position of the cell boundaries is also 
an important parameter which determines the progression of the summer tropical monsoons, the position of the subtropical dry regions and exerts a strong influence on mid- and high-latitude climate through Rossby wave propagation. Previous studies diagnosed a poleward extension of the Hadley cells under global warming using GCM outputs (Lu et al., 2007). A poleward extension was also found in the last decades using reanalyses ( $\mathrm{Hu}$ and $\mathrm{Fu}, 2007$ ), data from microwave soundings units (MSU) (Fu et al., 2006), and outgoing long-wave radiation (OLR) data sets ( $\mathrm{Hu}$ and $\mathrm{Fu}, 2007)$. The extension of the Hadley circulation was suggested to result from the dry static stability increase, which pushes poleward the baroclinic instability zones (Lu et al., 2007).

In this paper we further investigate these Hadley circulation changes, both in terms of weakening intensity and possible poleward shift of the tropical circulations. Our aim is to test the robustness of those changes, and better quantify them. Whereas the results of previous studies have been based on IPCC-scenario simulations (Held and Soden, 2006; Vecchi and Soden, 2007; Lu et al., 2007), we use in this paper the results of 18 coupled models, in the idealized conditions proposed by the CMIP3 experiments. We use results from both the pre-industrial control climate and the carbon dioxide $\left(\mathrm{CO}_{2}\right)$ doubling experiments. In Section 3, we check the robustness of the previously published results on the weakening and the poleward shift of the tropical circulation, and we provide additional statistics on the significance of the changes in the Hadley circulation strength, and in the Hadley cell's position. In Section 4, we use detailed outputs of a particular GCM, IPSL-CM4, to investigate quantitatively the mechanisms inducing the weakening and the poleward shift of the Hadley circulation. We propose a diagnostic methodology to investigate the effect of the dynamic and thermodynamic changes in the troposphere and their relationships with the Hadley circulation extension and intensity. Discussions and conclusion are given in Section 5.

\section{Data and methods}

Our analysis is based on two different data sets. First, we use the monthly surface pressure and meridional velocity, retrieved from the multimodel data set of the World Climate Research Programme's (WCRP) Coupled Model Intercomparaison Project Phase 3 (CMIP3) (available online at http://wwwpcmdi.llnl.gov). Then, we investigate the detailed daily outputs of the particular IPSL-CM4 AOGCM, including the pressure velocity, the zonal and meridional winds, and the temperature. We also used monthly vertical profiles of radiative and convective heating from forced simulations by the coupled model outputs.

Outputs from the following models are analysed: CGCM3.1(T47), CSIRO-Mk3.0, CNRM-CM3, GFDL-CM2.0, GFDL-CM2.1, GISS-EH, GISS-ER, FGOALS-g1.0, INM-CM
3.0, IPSL-CM4, MIROC3.2(hires), MIROC3.2 (medres), ECHAM5/MPI-OM, MRI-CGCM2.3.2, NCAR-CCSM3, NCAR-PCM, UKMO-HadCM3 and UKMO-HadGEM1. We limit our analysis to the model for which the three-dimensional data were available.

We have focused our diagnostics on two simulations that are part of CMIP3: (1) a control simulation, referred to as $1 \mathrm{CO}_{2}$, where all the greenhouse gases are set to their pre-industrial concentrations and (2) a climate change simulation in response to an idealized $1 \%$ yearly increase of the carbon dioxide $\left(\mathrm{CO}_{2}\right)$ concentration followed by a 40 -yr stabilization at a doubled $\mathrm{CO}_{2}$ concentration (with reference to the pre-industrial level). This second simulation is referred to later as $2 \mathrm{CO}_{2}$. All the diagnostics in the AOGCM intercomparison are applied to the control experiments and to two sequences of $2 \mathrm{CO}_{2}$ : (1) the last $30 \mathrm{yr}$ of the period of $1 \%$ yearly atmospheric $\mathrm{CO}_{2}$ increase (e.g. the transient climate response simulation to which we refer hereafter on as $2 \mathrm{CO}_{2}$-TCR) and (2) the period of $30 \mathrm{yr}$ beginning $40 \mathrm{yr}$ after the $\mathrm{CO}_{2}$ concentration has been stabilized at this doubled level. We refer to the later as $2 \mathrm{CO}_{2}$ STA (stabilized simulation). Following the availability of the models outputs, the transient simulation sequence $\left(2 \mathrm{CO}_{2}-\mathrm{TCR}\right)$ is analysed using all 18 models, but the stabilized simulation sequence $\left(2 \mathrm{CO}_{2}-\mathrm{STA}\right)$ is only analysed using 14 out of those 18 models.

The pre-industrial control simulation $1 \mathrm{CO}_{2}$ is not strictly analogous to present day climate, but we do not wish to add another level of complexity. Furthermore, we believe that processes occurring in climatology of the pre-industrial control simulation are equivalent to the ones characterizing present-day climate.

In addition to the model intercomparison, we use the coupled model IPSL-CM4 for more detailed diagnostics. For technical reasons, detailed IPSL-CM4 AOGCM outputs are studied for a period of $30 \mathrm{yr}$, beginning $300 \mathrm{yr}$ after the $\mathrm{CO}_{2}$ concentration has been stabilized at a doubled level. We refer later to this part of the simulation as $2 \mathrm{CO}_{2}-\mathrm{STA}^{\prime}$.

The resolution among the models varies from $4^{\circ}$ to $1.125^{\circ}$ in latitude and $5^{\circ}$ to $1.125^{\circ}$ in longitude. Our analysis is based on climatological monthly means, which cover the whole $1 \mathrm{CO}_{2}$ simulation and a $30 \mathrm{yr}$ period of the $2 \mathrm{CO}_{2}$ simulation. All the AOGCM results have been interpolated on the same grid for consistency.

A streamfunction $\psi$, defined in a zonally-averaged latitudeheight framework, is used to characterize the mean meridional circulation of the atmosphere (see Peixoto and Oort, 1982; Waliser et al., 1999 for the detailed procedure). As the Hadley cell varies along the seasonal cycle, we focus only on the two extreme seasons, DJF (Northern Hemisphere winter) and JJA (Southern Hemisphere winter), for which the winter Hadley cell is the strongest. The seasonal variations of the Hadley cells and their evolutions at the time of equinoxes are not studied in the present work. 

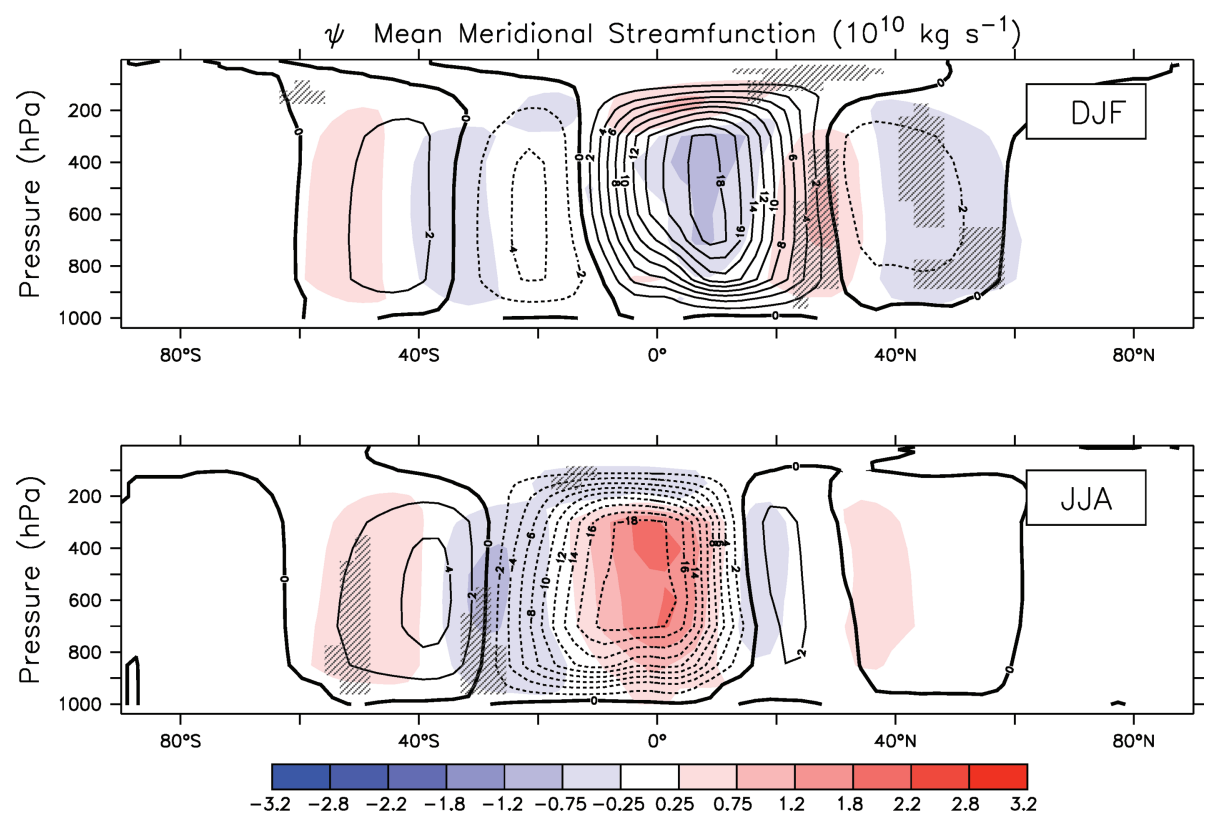

Fig. 1. Mean Meridional streamfunction $\left(10^{10} \mathrm{~kg} \mathrm{~s}^{-1}\right)$ for DJF (top) and JJA (bottom) for the pre-industrial $1 \mathrm{CO}_{2}$ simulation in contour. Contour interval is $2 \times 10^{10} \mathrm{~kg} \mathrm{~s}^{-1}$. The difference between the stabilized $\mathrm{CO}_{2}$ doubling simulation $2 \mathrm{CO}_{2}-\mathrm{STA}$ and the $1 \mathrm{CO}_{2}$ simulation is displayed in colour; the colour scale is shown at the bottom of the plots. Diagnostics are computed from the multimodel ensemble mean using 14 AR4 models. The striped zones are the regions where the level of statistical significance given by a Student t-test is larger than $90 \%$.

\section{Hadley circulation and its variation in the AR4 AOGCM global warming simulation}

\subsection{Changes in the pattern of the Hadley circulation}

As mentioned above, the mean meridional streamfunction $\psi$ is very often used as a proxy to describe the Hadley cells and their evolution. Its distribution, computed from the AR4 multimodel ensemble mean, is displayed with contours in Fig. 1, for DJF and JJA. The most remarkable structure is the dominant winter hemisphere Hadley cell extending from about $10^{\circ}$ in the summer hemisphere to about $30^{\circ}$ in the winter hemisphere.

Although there is a large dispersion among the 14 individual models (see Appendix A), the multimodel ensemble mean gives a fairly realistic Hadley circulation, compared with the diagnostics of Oort and Yienger (1996) from the NCEP reanalysis. Air rises at low latitudes near the ITCZ, and subsides at around $30^{\circ} \mathrm{N}$ or $30^{\circ} \mathrm{S}$. The maximum value of the DJF (JJA) streamfunction is $19.5 \times 10^{10} \mathrm{~kg} \mathrm{~s}^{-1}\left(20.5 \times 10^{10} \mathrm{~kg} \mathrm{~s}^{-1}\right)$. We note that the DJF value compares well with the one estimated by Mitas and Clement (2005) in the two reanalysis ERA40 and NECP2, for the period 1979-2003.

Before examining the changes of the mean meridional streamfunction from $1 \mathrm{CO}_{2}$ to $2 \mathrm{CO}_{2}$-STA (colour shadings in Fig. 1), we need to note that, with our conventions, the streamfunction corresponding to a clockwise circulation is positive, as in the Northern Hemisphere winter cell (in DJF), whereas the streamfunction corresponding to a counter-clockwise circulation is negative, as in the Southern Hemisphere winter cell (JJA). Thus, a strengthening of the Hadley cell corresponds to a positive value of the streamfunction change for DJF and a negative value for JJA.

A simple test of the statistical significance is performed. At the first order, the mean climate change of each of the 14 AR4 models of Fig. 1 is considered as an independent sample describing climate change. We performed a Student $t$-test to locate the changes stronger than a $90 \%$ level statistical significance, without accounting for the interannual variability of each model. The striped zones in Fig. 1 are the regions where the statistical significance given by a Student $t$-test is larger than the $90 \%$ level.

The main feature is the negative (positive) zone for DJF (JJA) in the centre of the winter Hadley cell, located around $5^{\circ}$ in the winter hemisphere. The centre of the winter Hadley cell corresponds to the maximum value of the streamfunction, the models tend to show a weakening of the Hadley cell. Indeed, thus the maximum absolute value of the streamfunction is an integrated indication of the Hadley circulation's intensity, since it is a measure of the total air mass entering the overturning circulation. This weakening of the mean meridional circulation is characterized by a $60 \%$ level of statistical significance given by a Student $t$-test. Thus, the weakening of the Hadley cells is weakly significant. This indicates that the weakening of the Hadley circulation in the AR4 models has a large dispersion.

Apart from the variation in intensity, we can also observe a poleward shift of both the winter and the summer Hadley cells. The poleward shift is diagnosed by a dipole at the edge of the cells. In the winter hemisphere, we diagnose an increase 
(decrease) zone in DJF (JJA) around $20^{\circ}$ to $30^{\circ}$, and a decrease (increase) zone around $40^{\circ}$ to $60^{\circ}$. Likewise, the summer Hadley cell poleward shift is seen by the decrease (increase) zone in DJF (JJA) around $30^{\circ}$ to $40^{\circ}$. We note that the winter Hadley cell poleward shift is systematic among the different models and significant for both DJF and JJA, as indicated by the striped zones. This shift is a manifestation of a poleward extension of the Hadley cell's extratropical limit. The poleward shift of the Hadley cell was demonstrated to be a robust feature affecting the tropical circulation and the extension of subtropical dry zones (Lu et al., 2007).

Other changes can also be observed in Fig. 1. In the upper part of the winter Hadley cell, a positive (negative) change is diagnosed for DJF (JJA). This corresponds to an upward shift of the Hadley cell. This shift is statistically significant at the $90 \%$ level at the poleward edge of the winter Hadley cell, as seen by the stripped zone on Fig. 1. The upper boundary of the Hadley cell corresponds to the tropopause of the atmosphere. Both the tropopause and the upper boundary of the Hadley cells rise in a warmer climate. This signal is very robust and agrees with many studies concerning the upward shift of the tropopause (Santer et al., 2003). The vertical extension of the tropopause is believed to be a consequence of surface temperature and lapse rate change under global warming.
Figure 1 does not reveal any systematic changes in the ascending branch of the Hadley cell, implying that the mean latitude of the ITCZ is unchanged under global warming conditions.

\subsection{Changes in the strength of the Hadley circulation}

In the following section, we present more quantitative diagnostics concerning both the intensity and the extent of the Hadley circulation. We choose to focus our study on the winter Hadley cells, and defer the summer Hadley cells changes for further work.

As mentioned earlier, the maximum absolute value of the mean meridional streamfunction is an integrated measure of the intensity of the Hadley circulation. Figure 2 is an illustration of the maxima $\psi_{\mathrm{DJF}}$ and $\psi_{\mathrm{JJA}}$ of the streamfunction absolute value changes with global warming in the $\mathrm{CO}_{2}$ doubling simulations, for DJF and JJA, respectively. As we choose to represent the absolute value of the streamfunction, only positive values are computed. Numerical values of the streamfunction maxima and minima, with the standard deviations among the AR4 AOGCM, are given in Table 2.

In Fig. 2, the dispersion among the GCMs, shown by the main bars, is large with a standard deviation of $2.8 \times 10^{10}$ and $4.6 \times 10^{10} \mathrm{~kg} \mathrm{~s}^{-1}$ for DJF and JJA, respectively. As an
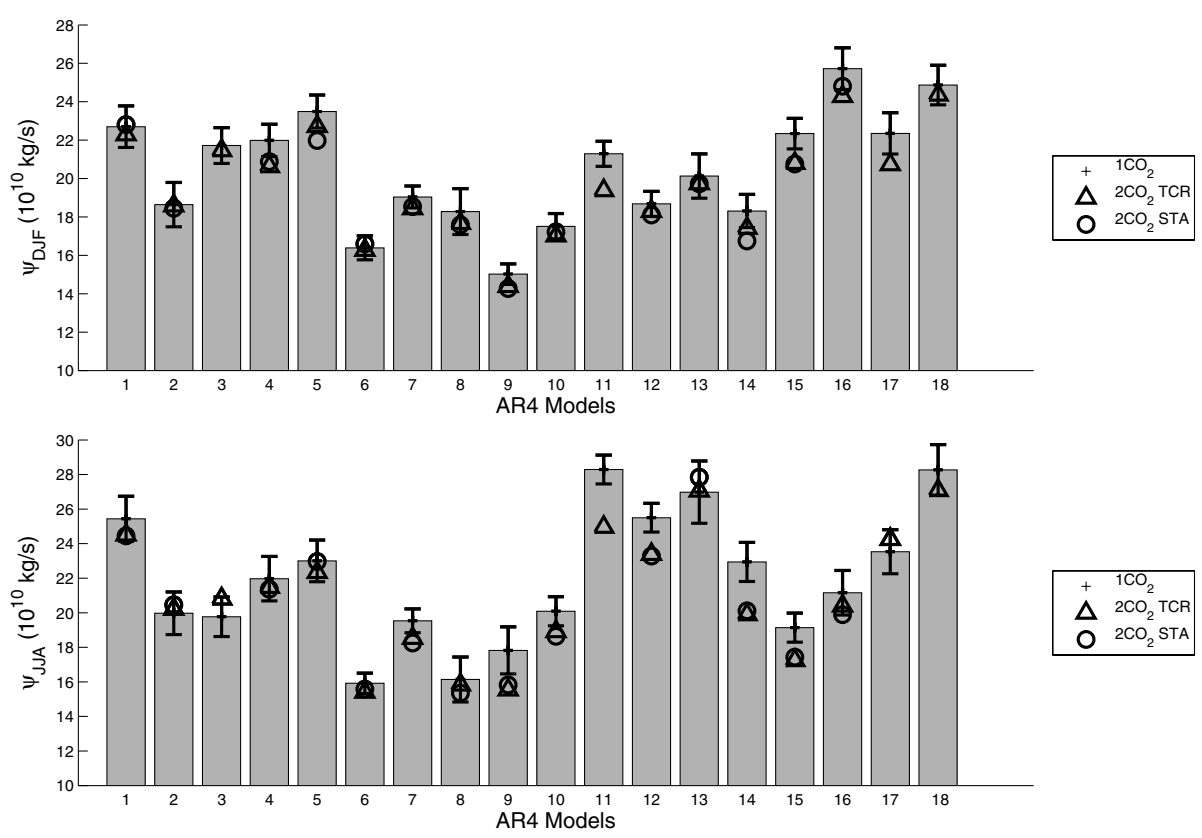

Fig. 2. Strength of the Hadley cell (in $10^{10} \mathrm{~kg} \mathrm{~s}^{-1}$ ), characterized by the maximum streamfunction absolute values $\psi_{\text {DJF }}$ (top) and $\psi_{\mathrm{JJA}}$ (bottom), for each of the AR4 models. Main bars represent the mean of the $1 \mathrm{CO}_{2}$ simulation. Error bars represent the standard deviation due to interannual variability. Results from $2 \mathrm{CO}_{2}$-STA and $2 \mathrm{CO}_{2}$-TCR are given by a triangle and a circle respectively. The AOGCM used are: (1) CGCM3.1(T47); (2) CSIRO-Mk3.0; (3) CNRM-CM3; (4) GFDL-CM2.0; (5) GFDL-CM2.1; (6) GISS-EH; (7) GISS-ER; (8) FGOALS-g1.0; (9) INM-CM 3.0; (10) IPSL-CM4; (11) MIROC3.2(hires); (12) MIROC3.2 (medres); (13) ECHAM5/MPI-OM; (14) MRI-CGCM2.3.2; (15) NCAR-CCSM3; (16) NCAR-PCM; (17) UKMO-HadCM3 and (18) UKMO-HadGEM1. 
illustration, the JJA Hadley cell strength $\psi_{\text {JJA }}$ of the 18 AR4 models used varies within a range from $15.9 \times 10^{10}$ to $28.3 \times$ $10^{10} \mathrm{~kg} \mathrm{~s}^{-1}$. The ability of the GCMs to represent the Hadley cell strength for DJF was examined by Mitas and Clement (2006) and was shown to vary with the various representations of the stability of the tropical troposphere. Nevertheless, the consequences of considering different base states of the Hadley circulation and their implication for climate sensitivity are still unclear, as no precise observations of the Hadley cells are available. The best measures are provided by the reanalysis data sets, which have different Hadley cell strength for the NCEP and the ERA40 reanalysis (Mitas and Clement, 2006).

The Hadley cells strength for $2 \mathrm{CO}_{2}$-TCR and $2 \mathrm{CO}_{2}$-STA are given by triangles and circle, respectively, in Fig. 2. Quantitative values of the mean change and its spread among the AR4 models, are reported in Table 2. The weakening of the Hadley circulation under global warming is of the order $4 \%$ for both DJF and JJA season. The changes of two period $2 \mathrm{CO}_{2}$-TCR and $2 \mathrm{CO}_{2}-\mathrm{STA}$ are quite similar. Nevertheless, in the $2 \mathrm{CO}_{2}$-STA simulation, the JJA Hadley cell weakens by $5 \%$ and the DJF cell weakening is smaller $(3.5 \%)$. The weakening is larger than the intermodel standard deviation for $2 \mathrm{CO}_{2}$-STA.

The intermodel dispersion is an important indicator but does not seem an appropriate reference to test the statistical significance of the changes in Hadley cells intensity in each model. Better references are constructed on the interannual variability of each individual GCM.

Without performing a formal test of the statistical significance, we display the interannual standard deviation of the Hadley cell strength for each individual GCM in the control $1 \mathrm{CO}_{2}$ simulation, in the form of error bars in Fig. 2. It appears that the Hadley cells strength for each GCM are rather stable. For most of the models, the interannual variability has the same order of magnitude as the climate change signal. However, for some models the climate change signal is stronger than the interannual variability.

In addition to the previous diagnostics, we investigate the time-series of the Hadley circulation strength of the $1 \mathrm{CO}_{2}$ and $2 \mathrm{CO}_{2}$ simulation, for the DJF and JJA seasons. For $1 \mathrm{CO}_{2}$, the trends of the pre-industrial control simulation are computed for a 150 -yr period. For $2 \mathrm{CO}_{2}$, the trends are computed over the $70 \mathrm{yr}$ of $1 \%$ yearly $\mathrm{CO}_{2}$ increase. Following the methodology of Mitas and Clement (2006), the trends are estimated using a linear least squares regression. The significance of the trends is computed by accounting for temporal autocorrelation in the time-series with adjusted standard error and degree of freedom, using the methodology given in Santer et al. (2000).

Table 1 gives the trends and their level of significance among the AR4 coupled GCM. Most models show a weakening of the Hadley cells during the period of $\mathrm{CO}_{2}$ increase. For DJF, 14 models out of 18 show a significant weakening. For JJA, 16 models out of 18 also show a significant weakening. The weakening of the Hadley cells has a level of significance usually stronger than
$99 \%$. Most of the models do not show any significant trend for the $1 \mathrm{CO}_{2}$ simulation.

\subsection{Changes in the Hadley cell extension and size}

To define the Hadley cell extension, we use the latitude at which the streamfunction takes the value 0.0 , interpolated on the latitude grid, at the pressure level of $500 \mathrm{hPa}$. For both DJF and $\mathrm{JJA}$, the streamfunction at $500 \mathrm{hPa}$ reaches the value 0.0 at three points between $45^{\circ} \mathrm{N}$ and $45^{\circ} \mathrm{S}$ : two at the extratropical edge of the Northern and Southern Hemisphere cells, and one between the two cells. The latitude of the extratropical boundary of the Northern and Southern Hemisphere Hadley cell is referred to as $\lambda_{\mathrm{N}}$ and $\lambda_{\mathrm{S}}$, respectively. $\lambda_{\mathrm{Eq}}$ refers to the boundary between the Northern and Southern Hemisphere cells.

These limits are computed for the winter cells only, as the winter cells are stronger than the summer cells and may have greater consequence on climate. In Fig. 3 , the equatorward $\left(\lambda_{\mathrm{Eq}}\right)$ and poleward $\left(\lambda_{N}\right.$ and $\left.\lambda_{S}\right)$ positions of the winter cells are displayed for all the analysed AR4 simulations. Continuous and dashed lines show the positions of the winter Hemisphere Hadley cells for each GCM during DJF and JJA. The interannual variability of each model for the $1 \mathrm{CO}_{2}$ simulation is shown by the error bars. Quantitative values of the mean Hadley cell positions averaged among the AR4 model, and the standard deviation between the models is given in Table 2 .

For the $\mathrm{CO}_{2}$ simulation, the spread of the diagnosed Hadley cell position is large, but we cannot assess what model is better, as no direct observations of the Hadley cells are available. The intermodel standard deviation among the individual AOGCM is $1.6^{\circ}$ and $0.9^{\circ}$ for the extratropical boundary of the DJF and JJA Hadley cell, respectively. The spread of the boundary between the Northern and the Southern cells is even larger with $2.3^{\circ}$ and $1.8^{\circ}$ for the standard deviation, respectively. The spread of $\lambda_{\mathrm{Eq}}$ may come from the bias affecting the shape and the position of the ITCZ among the AR4 models. The spread of $\lambda_{N}$ and $\lambda_{S}$ is less known; the ability of the GCMs to simulate these value is linked to the position of the jet stream.

The values of the DJF and JJA winter cell boundaries for $2 \mathrm{CO}_{2}$-TCR and $2 \mathrm{CO}_{2}$-STA are given by triangles and circles, respectively, for each individual GCM on Fig. 3. Quantitative values and relative changes compared with the $1 \mathrm{CO}_{2}$ simulation are reported in Table 2 . We can see a northward (southward) shift of the limits $\lambda_{N}\left(\lambda_{S}\right)$, for DJF (JJA), which is consistent with the features shown in Fig. 1. The descending branch of the JJA Hadley cell shows a larger poleward shift than the DJF cell, and the poleward shift reaches $0.9^{\circ}$ in JJA for $2 \mathrm{CO}_{2}-\mathrm{STA}$. For JJA, we note that most of the models show a poleward extension stronger than their interannual variability. The transient climate response $\left(2 \mathrm{CO}_{2}-\mathrm{TCR}\right)$ and the stabilized response $\left(2 \mathrm{CO}_{2}-\mathrm{STA}\right)$ show similar changes.

The boundary between the two Hadley cells $\left(\lambda_{\mathrm{Eq}}\right)$ also shows a shift toward the equator, and the winter Hadley cell 
Table 1. Linear trend $\left(10^{9} \mathrm{~kg} \mathrm{~s}^{-1}\right.$ per decade) in Hadley circulation strength, measured as the maximum value of the streamfunction absolute value $(\max (|\psi|))$. The trends are computed for $150 \mathrm{yr}$ of the $1 \mathrm{CO}_{2}$ simulation, and for the $70 \mathrm{yr}$ of $1 \%$ yearly $\mathrm{CO}_{2}$ increase of the $2 \mathrm{CO}_{2}$ simulation. The level of significance accounting for temporal autocorrelation in the time-series is given for each trend, following the methodology of Santer et al. (2000) with adjusted standard error and degree of freedom

\begin{tabular}{|c|c|c|c|c|c|c|c|c|}
\hline & \multicolumn{4}{|c|}{$1 \mathrm{CO}_{2}$} & \multicolumn{4}{|c|}{$2 \mathrm{CO}_{2}\left(+1 \% \mathrm{yr}^{-1} \mathrm{CO}_{2}\right)$} \\
\hline & \multicolumn{2}{|c|}{ DJF } & \multicolumn{2}{|c|}{ JJA } & \multicolumn{2}{|c|}{ DJF } & \multicolumn{2}{|c|}{ JJA } \\
\hline & trend & sign. & trend & sign. & trend & sign. & trend & sign. \\
\hline CGCM3.1(T47) & +0.61 & $99 \%$ & -0.75 & $99 \%$ & +0.08 & $27 \%$ & -2.98 & $100 \%$ \\
\hline CNRM-CM3 & +0.03 & $12 \%$ & +0.23 & $78 \%$ & -1.58 & $100 \%$ & -2.11 & $100 \%$ \\
\hline CSIRO-Mk3.0 & +0.09 & $37 \%$ & -0.10 & $33 \%$ & -1.16 & $99 \%$ & +0.17 & $52 \%$ \\
\hline GFDL-CM2.0 & +0.35 & $98 \%$ & -0.11 & $41 \%$ & -1.87 & $100 \%$ & -1.13 & $99 \%$ \\
\hline GFDL-CM2.1 & -0.09 & $48 \%$ & -0.03 & $12 \%$ & -1.85 & $100 \%$ & -0.93 & $99 \%$ \\
\hline GISS-EH & +0.36 & $98 \%$ & +0.23 & $99 \%$ & -0.71 & $99 \%$ & -0.10 & $100 \%$ \\
\hline GISS-ER & +0.08 & $57 \%$ & +0.07 & $40 \%$ & -0.00 & $2 \%$ & -0.90 & $100 \%$ \\
\hline FGOALS-g1.0 & +0.15 & $61 \%$ & +0.19 & $76 \%$ & +0.04 & $13 \%$ & -0.78 & $99 \%$ \\
\hline INM-CM3.0 & +0.10 & $59 \%$ & -0.31 & $86 \%$ & -1.36 & $100 \%$ & -2.67 & $100 \%$ \\
\hline IPSL-CM4 & -0.07 & $30 \%$ & -0.32 & $96 \%$ & +0.66 & $98 \%$ & -1.13 & $100 \%$ \\
\hline MIROC3.2(hires) & -0.08 & $44 \%$ & -0.60 & $99 \%$ & -0.94 & $100 \%$ & -3.87 & $100 \%$ \\
\hline MIROC3.2(medres) & +0.09 & $51 \%$ & +0.21 & $85 \%$ & -1.40 & $100 \%$ & -3.32 & $100 \%$ \\
\hline ECHAM5/MPI-OM & -0.16 & $35 \%$ & +0.41 & $82 \%$ & +0.69 & $74 \%$ & -0.55 & $85 \%$ \\
\hline MRI-CGCM2.3.2 & -0.07 & $30 \%$ & -0.05 & $19 \%$ & -1.58 & $100 \%$ & -2.55 & $100 \%$ \\
\hline NCAR CCSM3 & +0.06 & $28 \%$ & +0.04 & $27 \%$ & -2.45 & $100 \%$ & -0.66 & $99 \%$ \\
\hline NCAR PCM & +0.28 & $92 \%$ & -0.44 & $96 \%$ & -0.89 & $99 \%$ & -1.30 & $100 \%$ \\
\hline UKMO-HadCM3 & $+2.77^{\mathrm{a}}$ & $100^{\mathrm{a}} \%$ & -1.51 & $99 \%$ & -2.10 & $100 \%$ & +2.32 & $99 \%$ \\
\hline UKMO-HadGEM1 & -0.29 & $68 \%$ & -0.52 & $91 \%$ & -0.62 & $73 \%$ & -1.80 & $99 \%$ \\
\hline
\end{tabular}

${ }^{\mathrm{a}}$ We note that for UKMO-HadCM3, the time-series analysed for $1 \mathrm{CO}_{2}$ is only $50 \mathrm{yr}$ long, so the strengthening trend in the $1 \mathrm{CO}_{2}$ simulation is unlikely to be representative.

penetrates less deep into the summer Hemisphere. The shift of $\lambda_{\mathrm{Eq}}$ is stronger in DJF than in JJA, and is about half a degree. However, the changes of $\lambda_{\mathrm{Eq}}$ are less significant as the models show a poor agreement in the value for the control simulation. Furthermore, the changes are smaller than the interannual variability of each GCM (Fig. 3).

The net width of the Hadley circulation can be computed by $\left|\lambda_{N}-\lambda_{E q}\right|$ and $\left|\lambda_{S}-\lambda_{E q}\right|$ for DJF and JJA, respectively. Results are given in Table 2. In $2 \mathrm{CO}_{2}$-STA, it reveals a widening of the Hadley cells of $0.6^{\circ}$ for JJA, and a weak shrinking of $0.3^{\circ}$ for DJF. In JJA, a strong poleward shift of the descending branch comes together with a weaker shift of the ascending branch, and the Hadley cell widens. In DJF, the subsiding branch shifts less than the ascending branch, resulting in a net shrinking.

The results concerning the poleward shift agree well with the recent findings of Lu et al. (2007) who used the same parameter, the zero-value of the streamfunction at $500 \mathrm{hPa}$ but in the CMIP3 scenario simulations. Thus $\mathrm{CO}_{2}$ doubling simulations have the same characteristics as the scenario simulations, in terms of the Hadley cell extension.

\section{Mechanism of tropical circulation change in IPSL-CM4}

\subsection{The Hadley circulation change of the IPSL-CM4 AOGCM}

The slow down of the atmospheric circulation is studied and quantified in this section. For convenience, the analysis will be limited to only one coupled model the IPSL-CM4 coupled model. First, we study the variation of the Hadley cells simulated by this model to check whether the changes are similar to the AR4 multimodel mean.

The IPSL-CM4 AOGCM, use the Emanuel scheme (Emanuel, 1993) for parametrized convection and a parametrization of cloudiness associated with cumulus convection (Bony and Emanuel, 2001). The reader is referred to Hourdin et al. (2006) for an extensive description of the parametrized physics of the atmospheric part of the IPSL-CM4 model. The parametrized physics is well validated on tropical climate, and the use of IPSL-CM4 is appropriate for tropical climate studies. 
Fig. 3. Latitudinal position of the Hadley cell (in degrees), as characterized by $\lambda_{N}, \lambda_{S}$ and $\lambda_{\mathrm{Eq}}$, for each of the used AR4 models. The latitudinal position of the Northern (Southern) Hemisphere winter DJF (JJA) Hadley cell is represented by continuous (dashed) vertical lines. The position of $\lambda_{\mathrm{Eq}}$ indicates the tropical end of the winter hemisphere Hadley cell, and $\lambda_{N}$ or $\lambda_{S}$ indicate the extratropical end. Error bars represent the standard deviation due to interannual variability. Results from $2 \mathrm{CO}_{2}$-STA and $2 \mathrm{CO}_{2}$-TCR are given by triangles and circles, respectively. The AOGCMs used correspond to the number shown in the bottom. See Fig. 2 for the correspondence between numbers and model names.
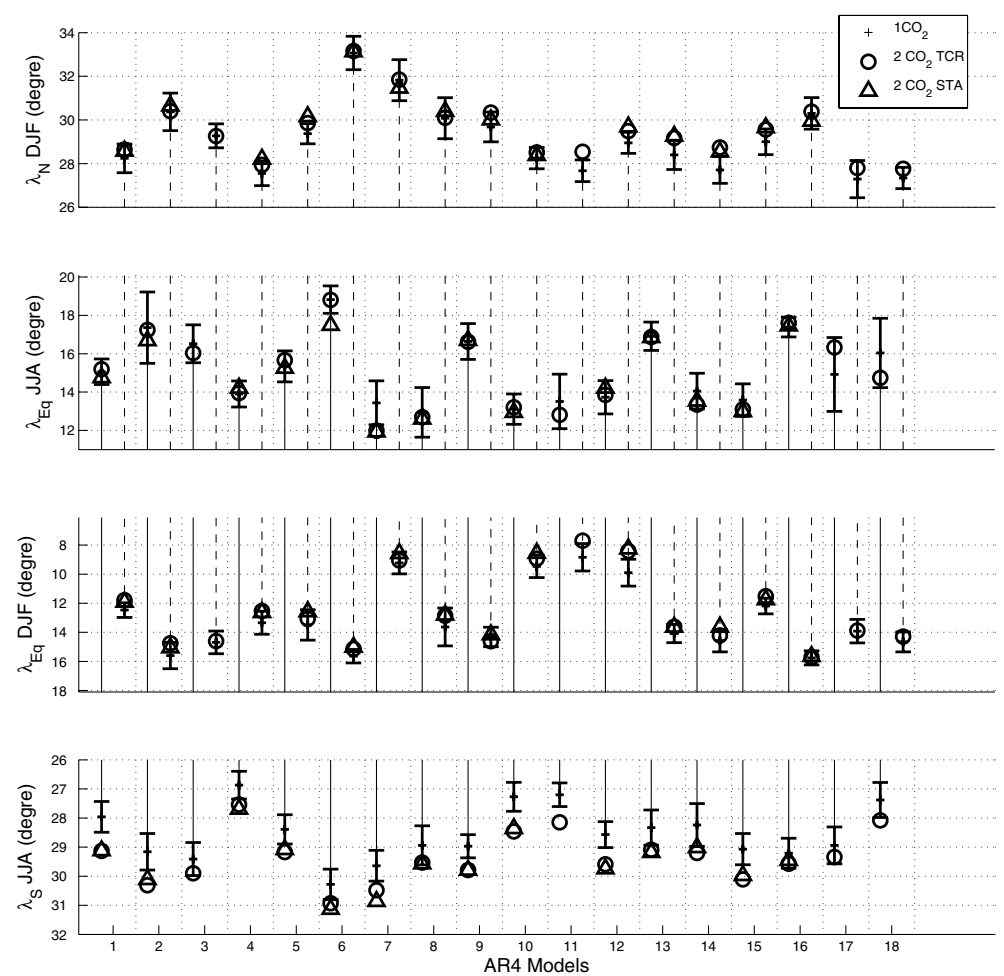

Table 2. Hadley circulation characteristics of the AR4 multi model ensemble mean: $\psi_{\text {DJF }}$ and $\psi_{\mathrm{JJA}}$ are the maximum absolute values of the mean meridional streamfunction, for the DJF and JJA season. $\lambda_{N}, \lambda_{S}$ and $\lambda_{E q}$ are the positions of the Hadley cells. $\left|\lambda_{N}-\lambda_{E q}\right|$ and $\left|\lambda_{S}-\lambda_{E q}\right|$ are the net width of the winter Hadley cells. The values are averaged values among the AR4 models. For $1 \mathrm{CO}_{2}, \sigma$ indicates the intermodel standard deviation. For $2 \mathrm{CO}_{2}-\mathrm{TCR}$ and $2 \mathrm{CO}_{2}$-STA, $\Delta$ and $\sigma(\Delta)$ indicate the variation $\Delta$ compared with $1 \mathrm{CO}_{2}$ simulation and the intermodel standard deviation of this variation, respectively

\begin{tabular}{|c|c|c|c|c|c|c|c|c|}
\hline & \multicolumn{2}{|c|}{$1 \mathrm{CO}_{2}$} & \multicolumn{3}{|c|}{$2 \mathrm{CO}_{2}-\mathrm{TCR}$} & \multicolumn{3}{|c|}{$2 \mathrm{CO}_{2}$-STA } \\
\hline & Mean & $\sigma$ & Mean & $\Delta$ & $\sigma(\Delta)$ & Mean & $\Delta$ & $\sigma(\Delta)$ \\
\hline$\psi_{\text {DJF }} 10^{10} \mathrm{~kg} \mathrm{~s}^{-1}$ & 20.5 & \pm 3.0 & 19.7 & $-3.7 \%$ & $\pm 2.4 \%$ & 19.2 & $-3.4 \%$ & $\pm 2.8 \%$ \\
\hline$\psi_{\mathrm{JJA}} 10^{10} \mathrm{~kg} \mathrm{~s}^{-1}$ & -22.0 & \pm 3.4 & -21.0 & $-4.4 \%$ & $\pm 5.2 \%$ & -20.1 & $-4.9 \%$ & $\pm 4.7 \%$ \\
\hline$\lambda_{\mathrm{N}} \mathrm{DJF}$ & $29.1^{\circ} \mathrm{N}$ & $\pm 1.6^{\circ}$ & $29.5^{\circ} \mathrm{N}$ & $0.4^{\circ}$ Northward & $\pm 0.3^{\circ}$ & $29.9^{\circ} \mathrm{N}$ & $0.4^{\circ}$ Northward & $\pm 0.4^{\circ}$ \\
\hline$\lambda_{\mathrm{S}} \mathrm{JJA}$ & $29.4^{\circ} \mathrm{S}$ & $\pm 0.9^{\circ}$ & $29.4^{\circ} \mathrm{S}$ & $0.8^{\circ}$ Southward & $\pm 0.3^{\circ}$ & $29.5^{\circ} \mathrm{S}$ & $0.9^{\circ}$ Southward & $\pm 0.3^{\circ}$ \\
\hline$\lambda_{\mathrm{Eq}} \mathrm{DJF}$ & $13.1^{\circ} \mathrm{S}$ & $\pm 2.3^{\circ}$ & $12.6^{\circ} \mathrm{S}$ & $0.5^{\circ}$ Northward & $\pm 0.4^{\circ}$ & $12.4^{\circ} \mathrm{S}$ & $0.6^{\circ}$ Northward & $\pm 0.4^{\circ}$ \\
\hline$\lambda_{\mathrm{Eq}} \mathrm{JJA}$ & $15.2^{\circ} \mathrm{N}$ & $\pm 1.8^{\circ}$ & $15.0^{\circ} \mathrm{N}$ & $0.2^{\circ}$ Southward & $\pm 0.6^{\circ}$ & $14.8^{\circ} \mathrm{N}$ & $0.3^{\circ}$ Southward & $\pm 0.6^{\circ}$ \\
\hline$\left|\lambda_{\mathrm{N}}-\lambda_{\mathrm{Eq}}\right| \mathrm{DJF}$ & $42.2^{\circ}$ & $\pm 3.0^{\circ}$ & $42.1^{\circ}$ & $-0.1^{\circ}$ & $\pm 0.5^{\circ}$ & $42.3^{\circ}$ & $-0.3^{\circ}$ & $\pm 0.4^{\circ}$ \\
\hline$\left|\lambda_{\mathrm{S}}-\lambda_{\mathrm{Eq}}\right| \mathrm{JJA}$ & $43.7^{\circ}$ & $\pm 2.4^{\circ}$ & $44.3^{\circ}$ & $+0.6^{\circ}$ & $\pm 0.6^{\circ}$ & $44.3^{\circ}$ & $+0.5^{\circ}$ & $\pm 0.6^{\circ}$ \\
\hline
\end{tabular}

The sequence of the $2 \mathrm{CO}_{2}$ simulation used in this section $2 \mathrm{CO}_{2}-\mathrm{STA}^{\prime}$ is different from the $2 \mathrm{CO}_{2}$-STA, as the IPSL-CM4 AOGCM is studied after $300 \mathrm{yr}$ of stabilization at $2 \mathrm{CO}_{2}$ levels. But the changes shown after $300 \mathrm{yr}$ of stabilization are similar to the one after $40 \mathrm{yr}$ of stabilization (not shown).

The same diagnostics as the ones applied to the AR4 multimodel mean are used for the IPSL-CM4 AOGCM. Figure 4 shows the IPSL-CM4 streamfunction for both the simulation $1 \mathrm{CO}_{2}$ (in contour) and the difference $2 \mathrm{CO}_{2}-\mathrm{STA}^{\prime}$ minus $1 \mathrm{CO}_{2}$ (in colour).
The $1 \mathrm{CO}_{2}$ streamfunction, and its variation with $\mathrm{CO}_{2}$ doubling, are shown by contour and colour shades in Fig. 4 . The meridional streamfunction of $1 \mathrm{CO}_{2}$ is very similar to the multimodel mean. Concerning the variation of the meridional streamfunction from $1 \mathrm{CO}_{2}$ to $2 \mathrm{CO}_{2}-\mathrm{STA}^{\prime}$, IPSL-CM4 presents a behaviour similar to the AR4 multimodel ensemble mean in JJA, while being rather different in DJF. For JJA, the IPSL-CM4 mean meridional streamfunction weakens between $10^{\circ} \mathrm{S}$ and $10^{\circ} \mathrm{N}$, which is consistent with the weakening of the multimodel ensemble mean streamfunction. Moreover, IPSL-CM4 shows a 

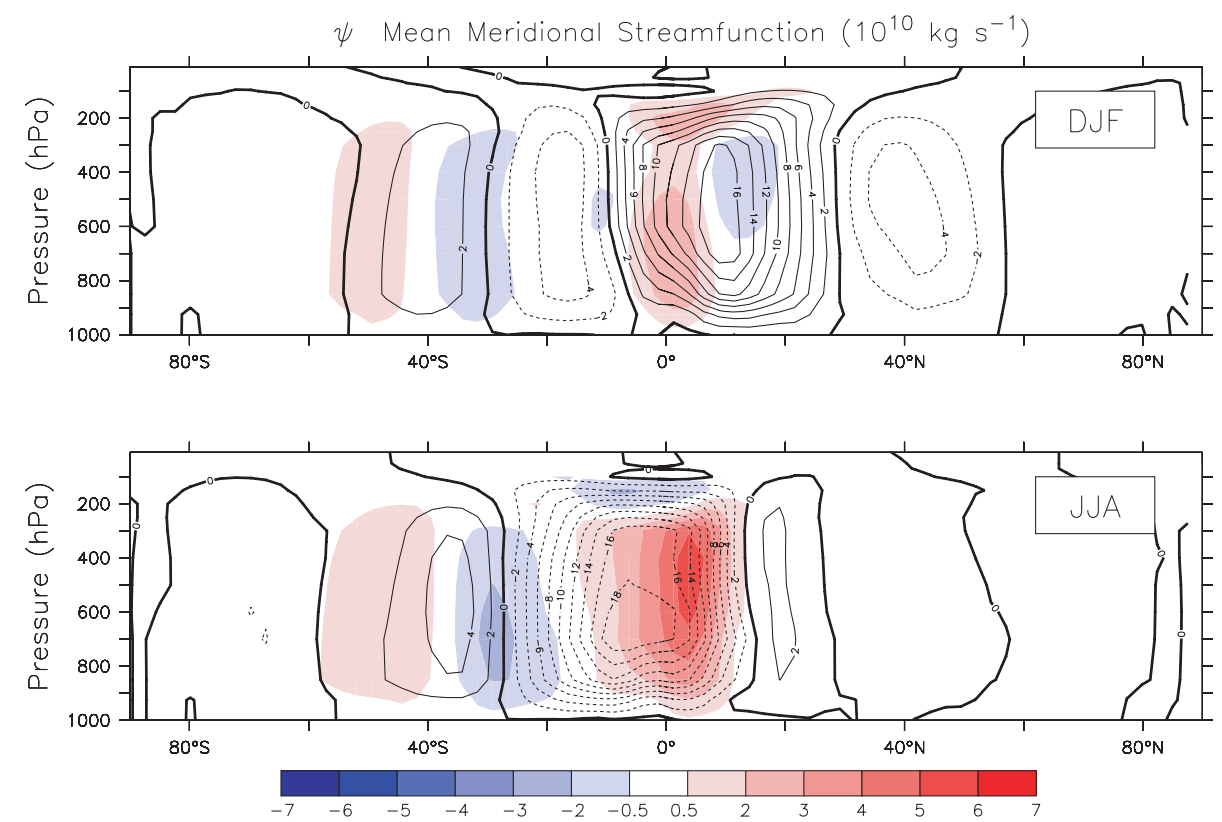

Fig. 4. Same as Fig. 1, but from IPSL-CM4 model. We note that the colour scale is different from Fig. 1.

Table 3. Same as Table 2 but for the IPSL-CM4 AOGCM

\begin{tabular}{lcccc}
\hline & $1 \mathrm{CO}_{2}$ & & \multicolumn{2}{c}{$2 \mathrm{CO}_{2}-\mathrm{STA}^{\prime}$} \\
\cline { 2 - 3 } & Mean & & Mean & $\Delta$ \\
\hline$\psi_{\mathrm{DJF}}\left(\times 10^{10} \mathrm{~kg} \mathrm{~s}^{-1}\right)$ & 17.4 & & 17.3 & $-0.5 \%$ \\
$\psi_{\mathrm{JJA}}\left(\times 10^{10} \mathrm{~kg} \mathrm{~s}^{-1}\right)$ & -20.0 & & -18.2 & $-8.6 \%$ \\
$\lambda_{N} \mathrm{DJF}$ & $28.5^{\circ} \mathrm{N}$ & & $28.6^{\circ} \mathrm{N}$ & $0.1^{\circ}$ Northward \\
$\lambda_{S} \mathrm{JJA}$ & $27.3^{\circ} \mathrm{S}$ & & $28.9^{\circ} \mathrm{S}$ & $1.5^{\circ}$ Southward \\
$\lambda_{\mathrm{Eq}} \mathrm{DJF}$ & $9.7^{\circ} \mathrm{S}$ & & $9.3^{\circ} \mathrm{S}$ & $0.4^{\circ}$ Northward \\
$\lambda_{\mathrm{Eq}} \mathrm{JJA}$ & $13.5^{\circ} \mathrm{N}$ & $12.9^{\circ} \mathrm{N}$ & $0.6^{\circ}$ Southward \\
\hline
\end{tabular}

dipole structure around $30^{\circ} \mathrm{S}$, consistent with the poleward extension of the winter Hadley cell. On the other hand, for DJF, IPSL-CM4 does not show any changes of the maximum streamfunction value, contrary to what was diagnosed in the other AR4 models. In Fig. 4, a clear strengthening of the circulation is observed for the ascending branch around $0^{\circ} \mathrm{N}-5^{\circ} \mathrm{N}$.

Numerical values of the Hadley circulation strength and positions, for IPSL-CM4, are given in Table 3, and compared with the other AR4 models (Table 2). The values for the $1 \mathrm{CO}_{2}$ control simulation show a reasonable agreement with the AR4 multimodel ensemble mean, however, the Hadley cells strength of IPSL-CM4 is somewhat weaker than in the other AR4 models. The extratropical boundaries of the DJF and the JJA winter Hadley cell agree with the other AR4 models, but the Hadley cells tend to be narrower than in the other models. The boundaries between the summer and the winter cell are also closer from the equator compared with the other AR4 models. The default was noted in the atmospheric component of the IPSLCM4 model by Hourdin et al. (2006), which noted that the jet positions were shifted equatorward compared with the ERA40 reanalysis data set.

Then, the relative changes of IPSL-CM4 for the $2 \mathrm{CO}_{2}-\mathrm{STA}^{\prime}$ simulation are compared with the changes of the $2 \mathrm{CO}_{2}$-STA simulation of the other AR4 mean. The JJA Hadley cell shows a weakening of $-8.6 \%$, which is stronger than that of the other models, but the DJF Hadley cell shows only little changes $(-0.5 \%)$. Likewise, the poleward shift of the Hadley winter cell's poleward position is also strong for JJA $\left(\lambda_{S}\right)$, but no changes are diagnosed for DJF $\left(\lambda_{N}\right)$. The shifts of $\lambda_{\mathrm{Eq}}$, the boundary between the Northern and Southern Hemisphere Hadley cell, are in good agreement with the other AR4 models.

In Table 2, the spread of the AR4 models is computed by the standard deviation of the AR4 models for the $1 \mathrm{CO}_{2}$ simulation and the differences with the $\mathrm{CO}_{2}$ doubling. The JJA changes of IPSL-CM4 tends to be stronger than the other AR4 models, but these changes fall into the spread of the other AR4 models for most of the proxies. On the other hand, the DJF changes are weak, and most of them do not fall into the AR4 model spread.

Figure 5 shows the zonal wind and its changes for IPSL-CM4. The zonal wind changes are coherent with the Hadley circulation changes in extension. The Southern Hemisphere subtropical jet is shifted poleward during the JJA simulation, as seen by the colour dipole at $40^{\circ} \mathrm{S}$, while the DJF zonal wind does not show any shifts.

The use in austral winter (JJA) of the IPSL-CM4 AOGCM is therefore pertinent to describe at least qualitatively, climate change mechanisms, which are likely to occur in most AR4 models. Whereas for boreal winter (DJF), the changes induced 

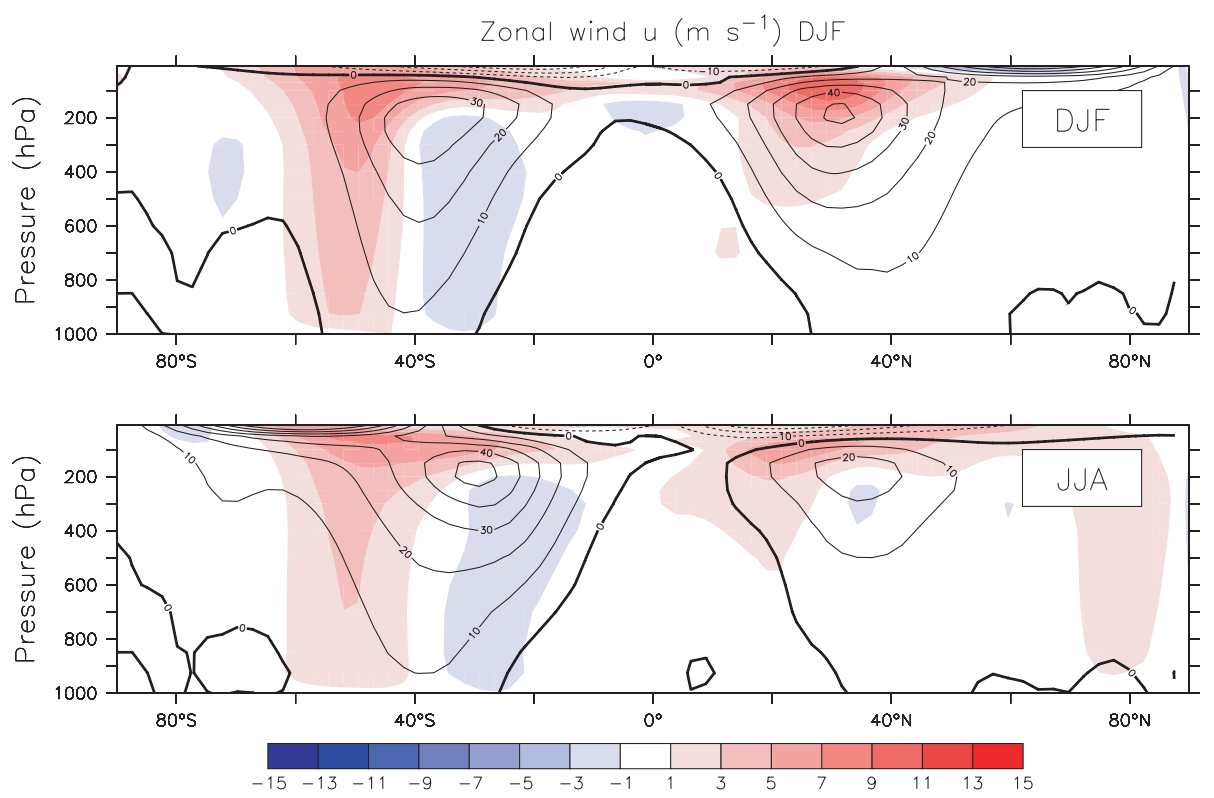

Fig. 5. Zonal mean wind in $\mathrm{m} \mathrm{s}^{-1}$, from IPSL-CM4 model. The value for the $1 \mathrm{CO}_{2}$ simulation is shown in contour. The colours indicate differences between the $2 \mathrm{CO}_{2} \mathrm{STA}^{\prime}$ and $1 \mathrm{CO}_{2}$ simulation.

by the greenhouse gases increase are different from the AR4 multimodel mean and are model-dependent.

\subsection{Analysis of the variability in the tropospheric zonal momentum and heat budget}

To investigate the changes of the Hadley circulation strength and position more quantitatively, we follow the methodology used by Seager et al. (2003). We compute the terms in the zonalmean zonal wind and temperature equation, dividing them into contributions from the zonal-mean circulation, stationary waves and transient eddies. The equation for the zonal wind is

$$
\begin{aligned}
\frac{\partial\langle\bar{u}\rangle}{\partial t} & =-\left(\frac{\langle\bar{v}\rangle}{a} \frac{\partial\langle\bar{u}\rangle}{\partial \phi}+\langle\bar{\omega}\rangle \frac{\partial \bar{u}}{\partial p}\right)+\left(f+\frac{\langle\bar{u}\rangle \sin \phi}{a \cos \phi}\right)\langle\bar{v}\rangle \\
& -\frac{1}{a \cos ^{2} \phi} \frac{\partial}{\partial \phi}\left(\left\langle\bar{u}^{*} \bar{v}^{*}\right\rangle \cos ^{2} \phi\right)-\frac{\partial}{\partial p}\left\langle\bar{u}^{*} \bar{\omega}^{*}\right\rangle \\
& -\frac{1}{a \cos ^{2} \phi} \frac{\partial}{\partial \phi}\left(\left\langle\overline{u^{\prime} v^{\prime}}\right\rangle \cos ^{2} \phi\right)-\frac{\partial}{\partial p}\left\langle\overline{u^{\prime} \omega \prime}\right\rangle \\
& -\overline{D\langle u\rangle} .
\end{aligned}
$$

Here, angle brackets indicate a zonal mean, the asterisk indicates departure from the zonal mean, overbars indicate a monthly mean and primes indicate departure from the monthly means. The variable $u$ is the zonal wind, $v$ the meridional wind and $\omega$ the vertical pressure velocity; $a$ is the radius of the earth, $\phi$ is latitude, $p$ is pressure, $f$ is the Coriolis parameter and $\overline{D\langle u\rangle}$ is a damping. The first term on the right-hand side of eq. (1) is the advection of the zonal-mean wind by the mean meridional circulation, the second term is the Coriolis torque, the third and fourth terms are forcings by momentum flux convergence within the stationary waves and the fifth and the sixth terms are the forcing by momentum flux convergence within the transient eddies.

The temperature equation is

$$
\begin{aligned}
\frac{\partial\langle\bar{T}\rangle}{\partial t} & =\underbrace{-\frac{\langle\bar{v}\rangle}{a} \frac{\partial\langle\bar{T}\rangle}{\partial \phi}-\langle\bar{\omega}\rangle\left(\frac{\partial\langle\bar{T}\rangle}{\partial p}-\frac{R\langle\bar{T}\rangle}{C_{p} p}\right)}_{\left\langle\delta T_{\mathrm{ADVh}}\right\rangle} \\
& -\underbrace{\frac{1}{a \cos \phi} \frac{\partial}{\partial \phi}\left(\left\langle\bar{v}^{*} \bar{T}^{*}\right\rangle \cos \phi\right)-\frac{\partial}{\partial p}\left\langle\bar{\omega}^{*} \bar{T}^{*}\right\rangle+\frac{R\left\langle\bar{\omega}^{*} \bar{T}^{*}\right\rangle}{C_{p} p}}_{\left\langle\delta T_{\mathrm{ADVv}}\right\rangle} \\
& -\underbrace{\frac{1}{a \cos \phi} \frac{\partial}{\partial \phi}(\langle\overline{v / T \prime}\rangle \cos \phi)-\frac{\partial}{\partial p}\langle\overline{\omega / T \prime}\rangle+\frac{R\langle\overline{\omega \prime T /}\rangle}{C_{p} p}}_{\left\langle\delta T_{\mathrm{STA}}\right\rangle} \\
+ & \underbrace{\frac{\langle\bar{Q}\rangle}{C_{p}},}_{\left\langle\delta T_{\mathrm{DIA}}\right\rangle}
\end{aligned}
$$

where, $T$ is the temperature, $R$ is the gas constant, $C_{p}$ the specific heat at constant pressure and $\langle Q\rangle$ is the diabatic heating (in units of $\mathrm{J} \mathrm{s}^{-1}$ ). In eq. (2), the first and the second terms on the righthand-side of eq. (2) are, respectively, the horizontal and vertical advection of the zonal-mean temperature by the meridional circulation $\left(\left\langle\delta T_{\mathrm{ADVh}}\right\rangle\right.$ and $\left.\left\langle\delta T_{\mathrm{ADVv}}\right\rangle\right)$. The third, forth and fifth terms are the contribution of the stationary waves $\left(\left\langle\delta T_{\mathrm{STA}}\right\rangle\right)$, the sixth, seventh and eighth terms are the contribution of the transient eddies ( $\left.\left\langle\delta T_{\mathrm{TRS}}\right\rangle\right)$. The last term represents the contribution from the diabatic heating $\left(\left\langle\delta T_{\text {DIA }}\right\rangle\right)$.

Each of the terms in eqs (1) and (2) are computed using daily outputs from the IPSL-CM4 coupled model, for $30 \mathrm{yr}$ of 
the simulations $1 \mathrm{CO}_{2}$ and $2 \mathrm{CO}_{2}$. Then, the monthly terms are averaged over the DJF and JJA seasons. The $30 \mathrm{yr}$ of the $2 \mathrm{CO}_{2}$ simulation correspond to the stabilized period $2 \mathrm{CO}_{2}-\mathrm{STA}^{\prime}$. The terms are computed at all pressure levels.

The variable $\langle\bar{Q}\rangle$ is first evaluated as a residual. As the direct diagnostics of the temperature tendencies from the radiative and convective schemes are not provided in the IPSL-CM4 database, we perform atmospheric only simulations with the atmospheric component of IPSL-CM4, that is, the GCM LMDZ4. These simulations use the climatological SST, sea ice extension and greenhouse concentration, from the coupled model IPSL-CM4, using the methodology illustrated in $\mathrm{Li}$ (2006). The simulations were performed over the period $1 \mathrm{CO}_{2}$ and $2 \mathrm{CO}_{2}-\mathrm{STA}^{\prime}$. The atmospheric simulations, using prescribed SST and sea ice from the coupled outputs, are run over $30 \mathrm{yr}$ and averaged to reduce the differences with the coupled model due to internal variability. These atmospheric simulations are able to mimic the results of the coupled model in terms of climatological precipitation and temperature in the mid-latitudes and tropics (not shown). The precipitation and the total radiative cooling of the atmospheric column show, respectively, differences of $0.7 \%$ and $1.5 \%$ in the tropical region (defined by the latitudinal limits $30^{\circ} \mathrm{N}$ and $30^{\circ} \mathrm{S}$ ), between the coupled and the forced atmospheric simulation. Thus, we can reasonably estimate the diabatic processes in the atmosphere through the outputs of the atmospheric simulations using prescribed SST and sea ice from the coupled model. The radiative cooling $\left\langle\overline{Q_{R}^{\prime}}\right\rangle$ and convective heating $\left\langle\overline{Q_{C}^{\prime}}\right\rangle$ terms, used in the following results, are from these atmospheric simulations using prescribed SST and sea ice from the coupled model.

Figure 6 shows the zonal mean zonal wind tendencies for the control simulation $1 \mathrm{CO}_{2}$, at the $400 \mathrm{hPa}$ height. In the winter cell the strongest zonal winds are found in the core of the subtropical jet, located at the poleward edge of the descending branch. The zonal mean meridional winds in the winter Hadley cell form a strong Coriolis torque. The Coriolis torque is stronger at the poleward edge of the Hadley cells as the Coriolis parameter increases with latitude. The momentum generated by the Coriolis torque, is cancelled by the momentum flux convergence within the transient eddies and the stationary waves. The stationary wave momentum flux convergence is weak except for the Northern Hemisphere in the DJF season. In the descending branches, the mean advection of momentum by the meridional circulation is strong. The mean advection at the $400 \mathrm{hPa}$ height is due to vertical component of the mean advection, which transports the zonal wind from atmospheric levels higher than $400 \mathrm{hPa}$ where the zonal wind is stronger. Thus, the vertical mean advection acts to reinforce the zonal wind in the descending branches of the Hadley cells.

Figure 7 gives the changes of the tendencies in the zonal mean zonal wind for the $\mathrm{CO}_{2}$ doubling. The changes are
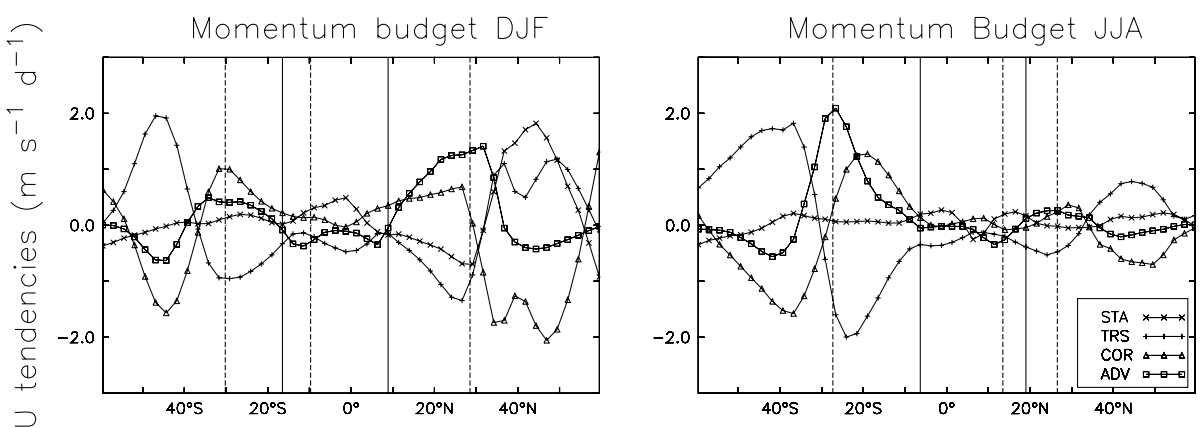

Fig. 6. Tendencies of the zonal mean zonal wind $\left(\mathrm{m} \mathrm{s}^{-1} \mathrm{~d}^{-1}\right)$ due to Coriolis torque (COR), mean advection (ADV), convergence of momentum within stationary waves (STA) and transient eddies (TRS). The zonal wind tendencies are computed for DJF (left-hand panel) and JJA (right-hand panel), in the model IPSL-CM4 for the pre-industrial control simulation $1 \mathrm{CO}_{2}$, at the $400 \mathrm{hPa}$ height. For reference, the Hadley cells positions are indicated by dashed lines: the thick dashed lines give $\lambda_{\mathrm{N}}, \lambda_{\mathrm{S}}$ and $\lambda_{\mathrm{Eq}}$ and the thin solid lines give the latitude of the maximum and minimum streamfunction.
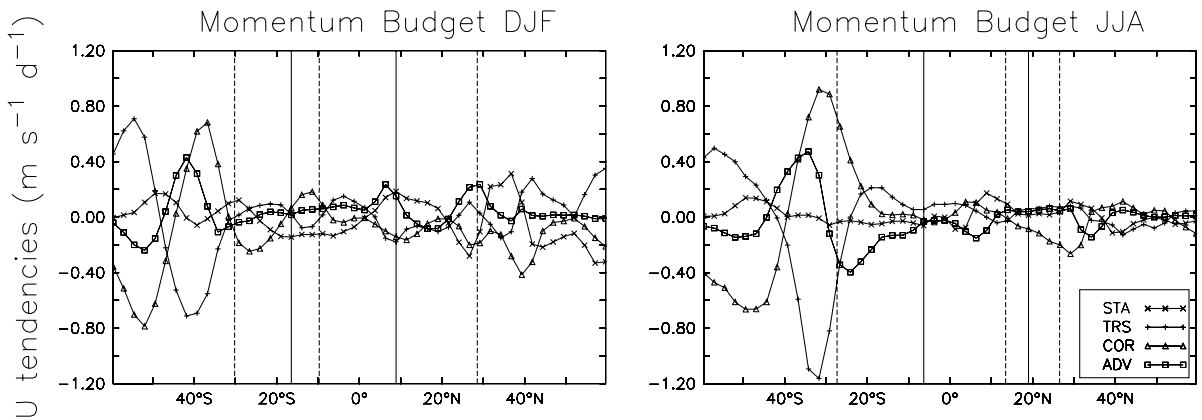

Fig. 7. Same as Fig. 6 but for the differences between the stabilized $\mathrm{CO}_{2}$ doubling simulation $\left(2 \mathrm{CO}_{2}-\mathrm{STA}^{\prime}\right)$ and the control simulation $1 \mathrm{CO}_{2}$. 
important only in the Southern Hemisphere. It corresponds to the subtropical jet and Hadley cells changes, which shift poleward only in the Southern Hemisphere, in IPSL-CM4 (Figs. 4 and 5). For JJA, the weakening of the zonal mean zonal wind at the poleward edge of the Southern Hemisphere Hadley cell, is clearly induced by the convergence of momentum flux within transient eddies, and to a lesser extent by the advective terms. Both terms explain the decrease of the zonal mean zonal wind between $20^{\circ} \mathrm{S}$ and $40^{\circ} \mathrm{S}$, the Coriolis torque being a damping factor of theses changes. For DJF, very few changes are diagnosed within the Hadley winter cell region.

From the zonal momentum budget analysis of IPSL-CM4 coupled model, it is the poleward shift of the momentum flux convergence within the transient eddies that induces the poleward shift of the Hadley cell for JJA. Therefore, the reasons explaining the poleward shift of the momentum flux convergence within transient eddies are crucial to understand the poleward shift of the Hadley cells under global warming. Lu et al. (2007) proposed that the increase of the gross static stability in the subtropical region acts to suppress baroclinic instability in these regions. The suppressed baroclinicity in subtropical regions causes the transient eddies momentum forcing to shift polewards. In the tropic, the increase in static stability is expected from simple application of the moist adiabatic lapse rate (Xu and Emanuel, 1989). As the water vapour loading of the atmosphere increases exponentially with temperature following the Clausius-Clapeyron equation, the moist lapse rate changes induces a stronger warming in the upper layer of the tropical troposphere than in the lower layers. Our results in the Southern Hemisphere, for JJA, agree this mechanism as the baroclinicity and momentum forcing by transient eddies shift poleward, which displaces the Hadley cells polewards.

However, in the Northern Hemisphere, for DJF, different processes act, as IPSL-CM4 does not show any changes in the extension of the Hadley cell. The subtropical jet strengthens in Fig. 5, but the momentum convergence within stationary waves and transient eddies shows only few changes in the Northern
Hemisphere, in the $2 \mathrm{CO}_{2}$ simulation. In DJF, the gross static stability of the atmosphere increases as a robust consequence of global warming, but the baroclinicity is not suppressed in the subtropical regions.

The dynamic mechanism that governs the changes in the baroclinicity, which in turns shifts the Hadley, is a crucial question that cannot be answered from our zonal momentum budget analysis alone. More investigation of this question is needed to understand the asymmetry in the stationary waves and transient eddy changes between the Northern and the Southern Hemisphere, in IPSL-CM4.

Figure 8 shows the zonal mean temperature tendencies diagnosed by eq. (2). In the ascending branch of the Hadley cells, there is a strong cancellation between the diabatic heating and the vertical advection, all other terms being negligible. In the descending branches, the diabatic heating and the vertical advection also strongly cancel each other, but the heat convergence within stationary waves and transient eddies also drives the vertical mean temperature advection. The stationary waves and transient eddies terms are particularly important at the poleward edges of the Hadley cells. The mean horizontal temperature advection is negligible. The heat convergence in the stationary wave is only important in the Northern Hemisphere, for the DJF season.

As the mean vertical velocity results from the diabatic heating and poleward heat flux within stationary waves and transient eddies, we write the zonal mean vertical pressure velocity as a function of the different temperature tendencies. The zonal mean vertical pressure velocity is

$$
\begin{aligned}
\langle\bar{\omega}\rangle & =\frac{1}{\left\langle S_{p}\right\rangle}\left(\left\langle\delta T_{\mathrm{ADVh}}\right\rangle+\left\langle\delta T_{\mathrm{STA}}\right\rangle+\left\langle\delta T_{\mathrm{TRS}}\right\rangle\right. \\
& \left.+\left\langle\delta T_{\mathrm{DIA}}\right\rangle\right) .
\end{aligned}
$$

Here, $\left\langle S_{p}\right\rangle$ is the zonal mean static stability parameter, defined as

$$
\left\langle S_{p}\right\rangle=\frac{\partial\langle\bar{T}\rangle}{\partial p}-\frac{R\langle\bar{T}\rangle}{C_{p} p}=-\frac{\langle T\rangle}{\langle\theta\rangle} \frac{\partial\langle\theta\rangle}{\partial p},
$$
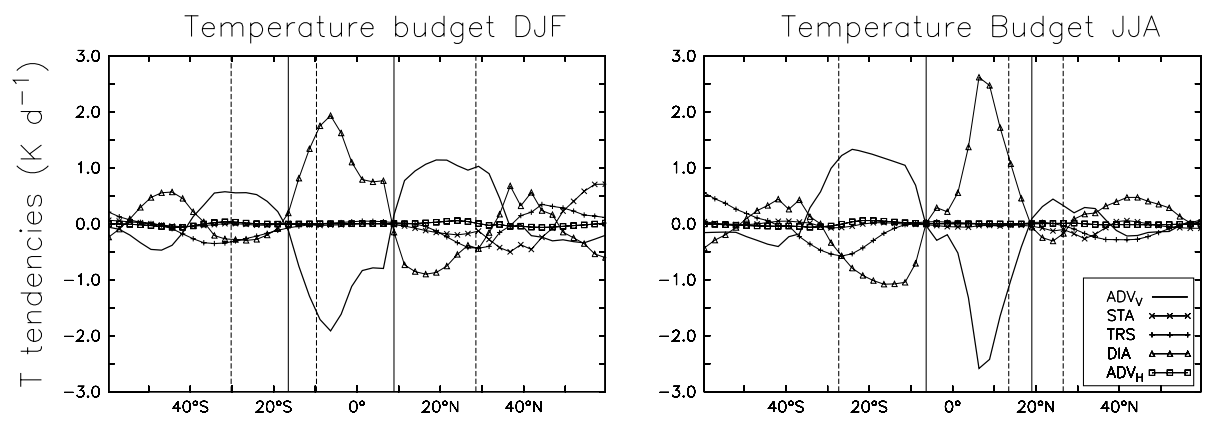

Fig. 8. Tendencies of the zonal mean temperature $\left(\mathrm{hPa} \mathrm{d}^{-1}\right.$ ) due to mean advection (ADV), heat convergence within stationary waves (STA), heat convergence within the transient eddies (TRS) and diabatic heating (DIA). The temperature tendencies are computed for DJF (left-hand panel) and JJA (right-hand panel), in IPSL-CM4 for the pre-industrial control simulation $1 \mathrm{CO}_{2}$, at the $500 \mathrm{hPa}$ height. For reference, the geometry of the Hadley cells is given by thick dashed and thin solid lines, as in Fig. 6. 

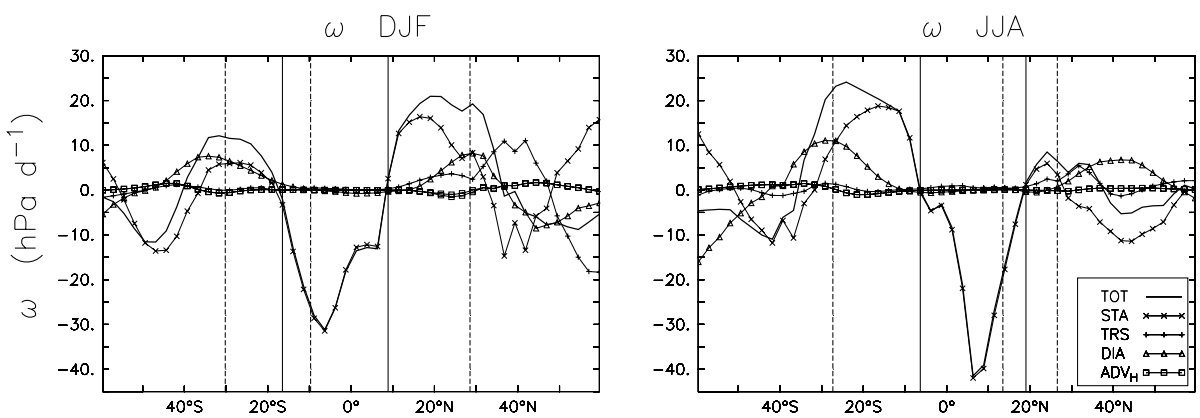

Fig. 9. Zonal mean vertical pressure velocity $\left(\mathrm{hPa} \mathrm{d}^{-1}\right)$ in the control simulation $\left(\mathrm{CO}_{2}\right)$, induced by mean meridional advection (ADV), heat convergence within stationary waves (STA), heat convergence within transient eddies (TRS) and diabatic heating (DIA). The zonal mean vertical pressure velocity is indicated with a thick line (TOT). The different components of the vertical pressure velocity are computed for DJF (left-hand panel) and JJA (right-hand panel), in IPSL-CM4, at the $500 \mathrm{hPa}$ height. For reference, the geometry of the Hadley cells is given by thick dashed and thin solid lines, as in Fig. 6.

where $\theta$ is the potential temperature. The static stability parameter $S_{p}$ is proportional but not equal to the Brunt Väisälä frequency, the buoyancy frequency of dry air. $S_{p}$ is a measure of the dry static stability of the atmosphere.

Figure 9 gives the different terms of eq. (3), for the simulation $1 \mathrm{CO}_{2}$. In the ascending branch of the Hadley cell, the vertical velocity is given by the vertical velocity induced by diabatic heating (DIA). Atmospheric convection releases latent heating, which balances the ascending velocity in the ascending branch of the Hadley cell. In the subsiding branches of the Hadley cell, part of the vertical velocity is also induced by diabatic heating; as the radiative cooling is strong, the air particles subside in the subtropical regions. The other part of the subsiding velocities, is induced by heat convergence within stationary waves and transient eddies. The stationary waves and transient eddies transport heat from subtropics to mid-latitudes and act to increase the subsidence. Lastly, we note that the mean meridional temperature advection has negligible effects on the zonal mean vertical velocity.
The changes during the $\mathrm{CO}_{2}$ doubling are investigated by a linearization of eq. (3):

$$
\begin{aligned}
\Delta\langle\bar{\omega}\rangle & \approx-\frac{\Delta\left\langle S_{p}\right\rangle}{\left\langle S_{p}\right\rangle_{1 \mathrm{CO}_{2}}}\langle\bar{\omega}\rangle_{1 \mathrm{CO}_{2}}+\frac{\Delta\left\langle\delta T_{\mathrm{ADV}}\right\rangle}{\left\langle S_{p}\right\rangle_{1 \mathrm{CO}_{2}}} \\
& +\frac{\Delta\left\langle\delta T_{\mathrm{STA}}\right\rangle}{\left\langle S_{p}\right\rangle_{1 \mathrm{CO}_{2}}}+\frac{\Delta\left\langle\delta T_{\mathrm{TRS}}\right\rangle}{\left\langle S_{p}\right\rangle_{1 \mathrm{CO}_{2}}}+\frac{\Delta\left\langle\delta T_{\mathrm{DIA}}\right\rangle}{\left\langle S_{p}\right\rangle_{1 \mathrm{CO}_{2}}}
\end{aligned}
$$

Here, $1 \mathrm{CO}_{2}$ denotes the mean value for the control simulation $1 \mathrm{CO}_{2}$, where greenhouse gases are set to their preindustrial concentration, and $\Delta$ denotes the differences between the $\mathrm{CO}_{2}$ doubling simulation $2 \mathrm{CO}_{2}$ and the control simulation $1 \mathrm{CO}_{2}$.

Figure 10 shows the changes of the zonal mean vertical pressure induced by the different terms of eq. (5). As the heat convergence within the stationary waves and the transient eddies are important only in the subsiding branches of the Hadley cells, the processes are somewhat different in the ascending and subsiding branches.
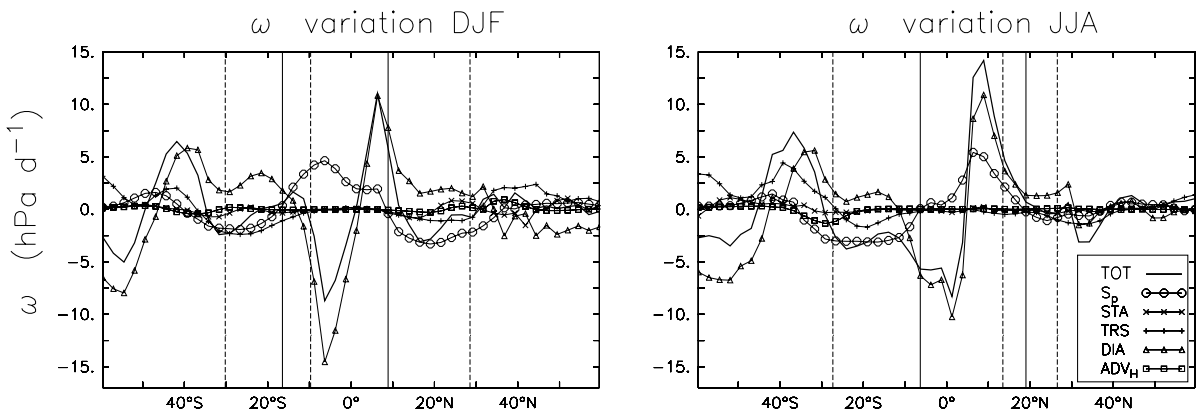

Fig. 10. Changes in the zonal mean vertical pressure velocity $\left(\mathrm{hPa} \mathrm{d}^{-1}\right)$ in the stabilized $\mathrm{CO}_{2}$ doubling simulation $\left(2 \mathrm{CO}_{2} \mathrm{STA}^{\prime}\right)$, induced by mean meridional advection (ADV), heat convergence within stationary waves (STA), heat convergence within transient eddies (TRS), diabatic heating (DIA) and static stability (Sp). The changes of the zonal mean vertical pressure velocity are indicated with a thick line. The different components of the vertical pressure velocity changes are computed for DJF (left-hand panel) and JJA (right-hand panel), in IPSL-CM4, at the 500 hPa height. For reference, the geometry of the Hadley cells is given by thick dashed and thin solid lines, as in Fig. 6. 
In the subsiding branch, the heat convergence within transient eddies weakens and the dry static stability increases. These changes reduce the subsidence, while the stronger radiative cooling in the troposphere acts as a damping. In JJA, the changes in dry static stability and heat convergence within transient eddies are stronger than the diabatic heating changes, resulting in a weakening of the subsiding velocities. Whereas in DJF, dry static stability heat convergence within transient eddies cancel the diabatic heating changes, resulting in little changes in subsidence. Our results confirms the previous studies of Knutson and Manabe (1995) and Sugi et al. (2002), as we show that the strong dry static stability increase, is responsible for the global decrease of the atmospheric circulation.

\subsection{Hadley circulation changes diagnosed by the temperature equation}

To diagnose the effect of each term of eq. (5), separately averaged over the ascending and the subsiding branches, an approach is built using the proxy of the Hadley circulation strength defined in the previous section. The mean meridional streamfunction $\psi$ is defined as

$\langle\bar{\omega}\rangle=-\frac{g}{2 \pi a^{2} \cos \phi} \frac{\partial \psi}{\partial \phi}$,

$\langle\bar{v}\rangle=\frac{g}{2 \pi a \cos \phi} \frac{\partial \psi}{\partial p}$.

Most of the studies use the zonal mean meridional wind $\langle\bar{v}\rangle$ to compute the mean meridional streamfunction. As the vertical pressure velocity in the GCM is usually diagnosed through the mass conservation equation, the use of vertical wind implies more interpolations. Nevertheless, we found that the use of vertical velocity to compute the streamfunction gives fairly similar values for the position of the Hadley cells.

To investigate the link between the vertical pressure velocity and the Hadley cells, we compute the mean meridional streamfunction using the zonal mean vertical pressure velocity $\langle\bar{\omega}\rangle$. We compute the positions of the winter Hadley cell, $\lambda_{\mathrm{N}}$ and $\lambda_{\mathrm{Eq}}$ (DJF) and $\lambda_{\mathrm{S}}$ and $\lambda_{\mathrm{Eq}}$ (JJA). The separation between the ascending and the subsiding branches is provided by $\lambda_{\max }$ and $\lambda_{\min }$, the latitudes where the streamfunction are maximum and minimum, for DJF and JJA, respectively. Then, we integrate between the two boundaries corresponding to each branch of the winter Hadley cells. For instance, in the DJF winter hemisphere ascending branch,

$\max (|\psi|)=\int_{\lambda_{N}}^{\lambda_{\max }} \frac{2 \pi a^{2}}{g}\langle\bar{\omega}\rangle \cos \phi \mathrm{d} \phi$.

We note that our analysis is performed on the winter Hadley cell and not on the summer cell, as we intend to investigate the maximum value of the streamfunction located in the winter cell.

Then, we use eq. (3) to write the zonal mean vertical wind as a function of the different temperature tendencies terms in eq.
(8). We can show that (see Appendix C),

$$
\begin{aligned}
\max (|\psi|) & =\frac{A_{u(d)}}{\left.g S_{p}\right|_{u(d)}} \overbrace{\left.\delta T_{\mathrm{ADV}}\right|_{u(d)}}^{\psi_{\mathrm{ADV}}}+\overbrace{\left.\delta T_{\mathrm{STA}}\right|_{u(d)}}^{\psi_{\mathrm{STA}}} \\
& +\overbrace{\left.\delta T_{\mathrm{TRS}}\right|_{u(d)}}^{\psi_{\mathrm{TRS}}}+\overbrace{\left.\delta T_{\mathrm{DIA}}\right|_{u(d)}}^{\psi_{\mathrm{DIA}}}+\overbrace{o(\max (|\psi|))}^{o(\psi)} .
\end{aligned}
$$

Here, $A_{u}$ and $A_{d}$ are the net area covered by the ascending and subsiding branch of the Hadley circulation, respectively. The averaging over the ascending and subsiding branches of the winter Hadley cells are indicated by vertical bars with subscripts $u$ (upward) and $d$ (downward), respectively. For instance, $\left.S_{p}\right|_{u}$ is the mean dry static stability averaged in the ascending branch of the Hadley cell.

The first term of eq. (9) is the effect of horizontal advection of temperature on the mean meridional circulation. The second and the third terms are the effects of heat convergence in the stationary waves and transient eddies, respectively. The fourth term represents the effect of diabatic heating. We can demonstrate that the last term, $o(\max (|\psi|))$, is a small residual term reflecting the small departure of the static stability from a constant value in the winter Hadley cell. Then, the effect of diabatic heating $\left(\psi_{\text {DIA }}\right)$ is divided into a radiative ( $\left.\psi_{\text {Rad }}\right)$ and a convective $\left(\psi_{\mathrm{Con}}\right)$ part, using the decomposition of the total diabatic heating into convective heating and radiative cooling $\left(\langle\bar{Q}\rangle \approx\left\langle\overline{Q_{R}^{\prime}}\right\rangle+\left\langle\overline{Q_{C}^{\prime}}\right\rangle\right)$.

Figure 11 shows the different terms of eq. (9), separately for the ascending and descending branches of the winter Hadley cell, at the $500 \mathrm{hPa}$ height. The upward mass flux in the ascending branch of the Hadley cell, diagnosed from the vertical pressure velocity is $17.9(19.6) \times 10^{10} \mathrm{~kg} \mathrm{~s}^{-1}$ for DJF (JJA). These values show a good agreement with the winter-hemisphere maximum absolute streamfunction computed from the meridional wind shown in Table 3. We also verify that the mass circulation diagnosed in the Hadley cell forms a closed system: the net ascending mass flux found in the ascending branch of the Hadley cell is almost equal to the subsiding mass flux found in the subsiding branch with differences smaller than $0.2 \%$.

Over the ascending branch of the Hadley cell, the mass flux closely follows the value given by the diabatic heating term. Over the subsiding branch of the Hadley cell, the stronger forcing is the diabatic heating, but the transient eddy and the stationary eddies heat divergences provide also one third (quarter) of the cooling for the descent of air for DJF (JJA).

In Fig. 11, we show with the striped bars the values of mass flux induced by radiative cooling and convective heating, using outputs of forced atmospheric simulation using prescribed SST and sea ice from the coupled model IPSL-CM4. Over the ascending branches, the latent heat has the strongest contribution to the total diabatic heating, and the radiative cooling tends to decrease the contribution of the diabatic heating in the mass flux. In the subsiding branches, only little convection is found, and the subsidence mainly results from radiative cooling. 

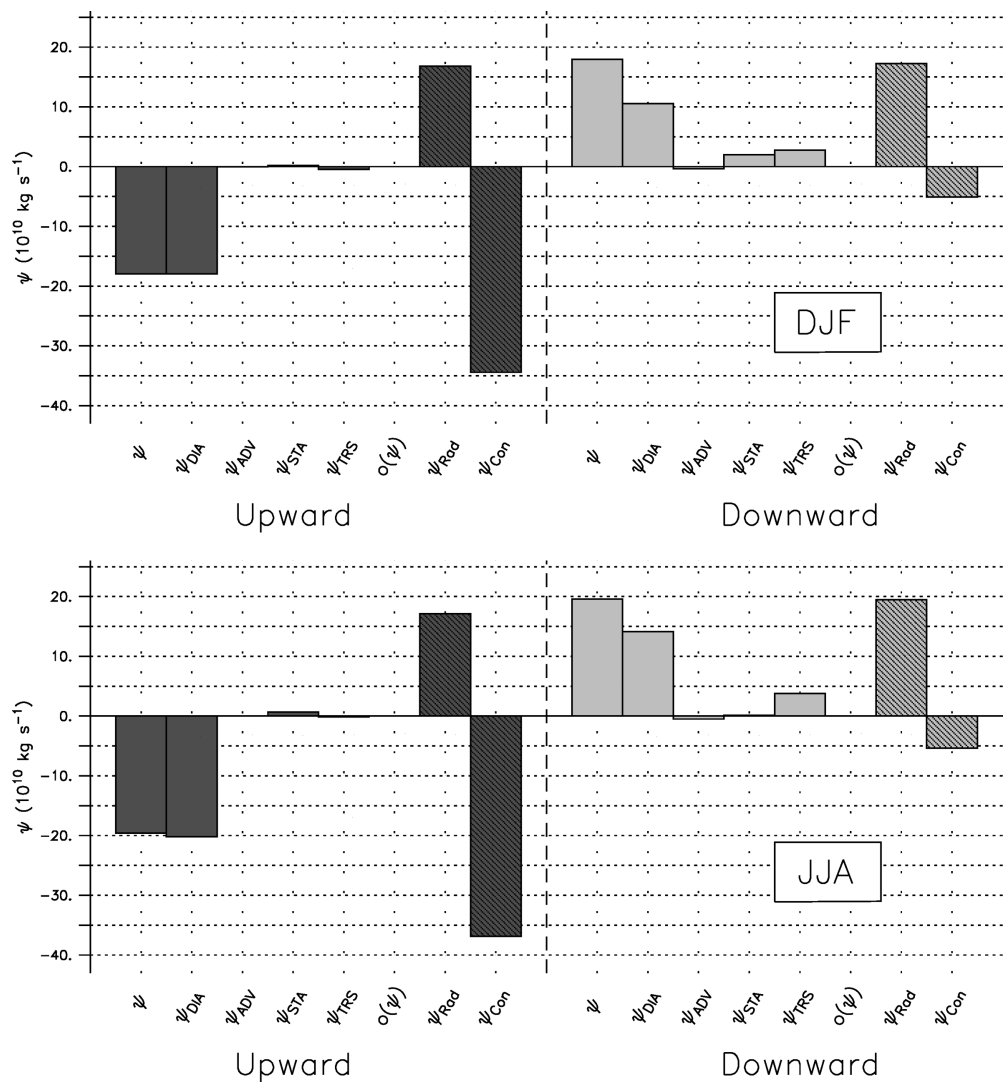

Fig. 11. Histogram of the different terms involved in the mean meridional circulation strength $\psi$, in IPSL-CM4. The upward and downward parts correspond to the ascending and subsiding branches of the winter Hemisphere Hadley cell. $\psi_{\text {ADV }}, \psi_{\text {STA }}$, $\psi_{\text {TRS }}$ and $\psi_{\text {DIA }}$ correspond to the effects of horizontal advection, heat flux convergence within stationary waves, heat flux convergence within transient eddies and diabatic heating, respectively. $o(\psi)$ is the residual of our decomposition. $\psi_{\text {Rad }}$ and $\psi_{\text {Con }}$, respectively, correspond to the effect of the radiative and convective parts of the diabatic heating diagnosed in the forced atmospheric simulations that mimic the coupled model IPSL-CM4. Upper panel is for DJF, lower panel for JJA.
In the subsiding branch, the convection mainly results form the zonal asymmetries of the ITCZ and a much smaller part comes from mid-latitude perturbations. This convection acts to decrease the subsiding mass flux. Finally, we note that DJF and JJA are very similar, except for the stationary waves that are negligible in the Southern Hemisphere Hadley cell.

The variation of the mass flux during the $\mathrm{CO}_{2}$ doubling is investigated using a linearization of eq. (9):

$$
\begin{aligned}
& \frac{\Delta \max (|\psi|)}{\max (|\psi|)}=-\overbrace{\frac{\left.\Delta S_{p}\right|_{u(d)}}{\left.S_{p}\right|_{u(d)}}}^{\Delta \psi_{S p}}+\overbrace{\frac{\Delta A_{u(d)}}{A_{u(d)}}}^{\Delta \psi_{A}} \\
& +\overbrace{\frac{\left.\Delta \delta T_{\mathrm{ADV}}\right|_{u(d)}}{\left.\delta T_{\mathrm{ADV}}\right|_{u(d)}+\left.\delta T_{\mathrm{STA}}\right|_{u(d)}}+\overbrace{\left.\Delta \delta T_{\mathrm{STA}}\right|_{u(d)}}^{\Delta \psi_{\mathrm{STA}}}+\overbrace{\left.\Delta \delta T_{\mathrm{TRS}}\right|_{u(d)}}^{\left.\Delta \psi_{\mathrm{TRS}}\right|_{u(d)}+\left.\delta T_{\mathrm{DIA}}\right|_{u(d)}}+\overbrace{\left.\Delta \delta T_{\mathrm{DIA}}\right|_{u(d)}}^{\Delta \psi_{\mathrm{DIA}}}} \\
& +o\left(\frac{\Delta \max (|\psi|)}{\max (|\psi|)}\right) .
\end{aligned}
$$

Figure 12 shows the different terms of eq. (10), at $500 \mathrm{hPa}$, for the two seasons DJF and JJA. The Hadley circulation changes at $500 \mathrm{hPa}$ show a $0.5 \%$ and $10.9 \%$ weakening for DJF and JJA, which are similar to the ones illustrated in Table 3.

Using eq. (10), we are able to decompose the changes in the atmosphere that explain the Hadley circulation changes.
The robust mechanisms already demonstrated by Knutson and Manabe (1995) and Sugi et al. (2002) are diagnosed. First, the dry static stability strongly increases in IPSL-CM4, which weakens the Hadley cells for DJF and JJA. Then the tropospheric radiative cooling increases due to higher water vapour loading of the troposphere. The stronger radiative cooling induces stronger subsiding velocities in the subsiding branch and weaker updraft in the ascending branch. But the radiative cooling changes are weaker than the dry static stability changes; therefore, the Hadley circulation weakens.

Figure 10 shows that other terms, less investigated, also have a strong contribution to the Hadley circulation change. The areas covered by the ascending and the subsiding branches show strong changes. During the $\mathrm{CO}_{2}$ doubling simulation, the ascending branch of the winter Hadley cell is narrower and the subsiding branch is wider. The changes in the relative fraction between the ascending and descending branches are responsible for a weakening of the mass flux in the ascending branch and a strengthening in the subsiding branch.

The latent heating reveals striking changes, for the two seasons DJF and JJA. For DJF, the latent heating strongly increases $(+38 \%)$ in the ascending branch of the Hadley cell. For JJA, latent heating also increases $(+10 \%)$, even if the increase is smaller than the DJF changes. The latent heating in the atmosphere is usually regarded as a consequence of the dynamic 
Fig. 12. Histogram of the different terms involved in the change of the mean meridional circulation strength $(\Delta \psi)$ during the $\mathrm{CO}_{2}$ doubling simulation $\left(2 \mathrm{CO}_{2} \mathrm{STA}\right)$, in IPSL-CM4. The upward and downward parts correspond to the ascending and subsiding branches of the winter Hemisphere Hadley cell. $\Delta \psi_{S p}, \Delta \psi_{\mathrm{ADV}}, \Delta \psi_{\mathrm{STA}}$, $\Delta \psi_{\text {TRS }}$ and $\Delta \psi_{\text {DIA }}$ correspond to the effects of dry static stability, horizontal advection, heat flux convergence within stationary waves, heat flux convergence within transient eddies and diabatic heating, respectively. $o(\Delta \psi)$ is the residual of the decomposition. $\Delta \psi_{\text {Rad }}$ and $\Delta \psi_{\text {Con }}$ correspond, respectively, to the effect of the radiative and convective part of the diabatic heating diagnosed in forced atmospheric simulations that mimic IPSL-CM4. Upper panel is for DJF, lower panel for JJA.
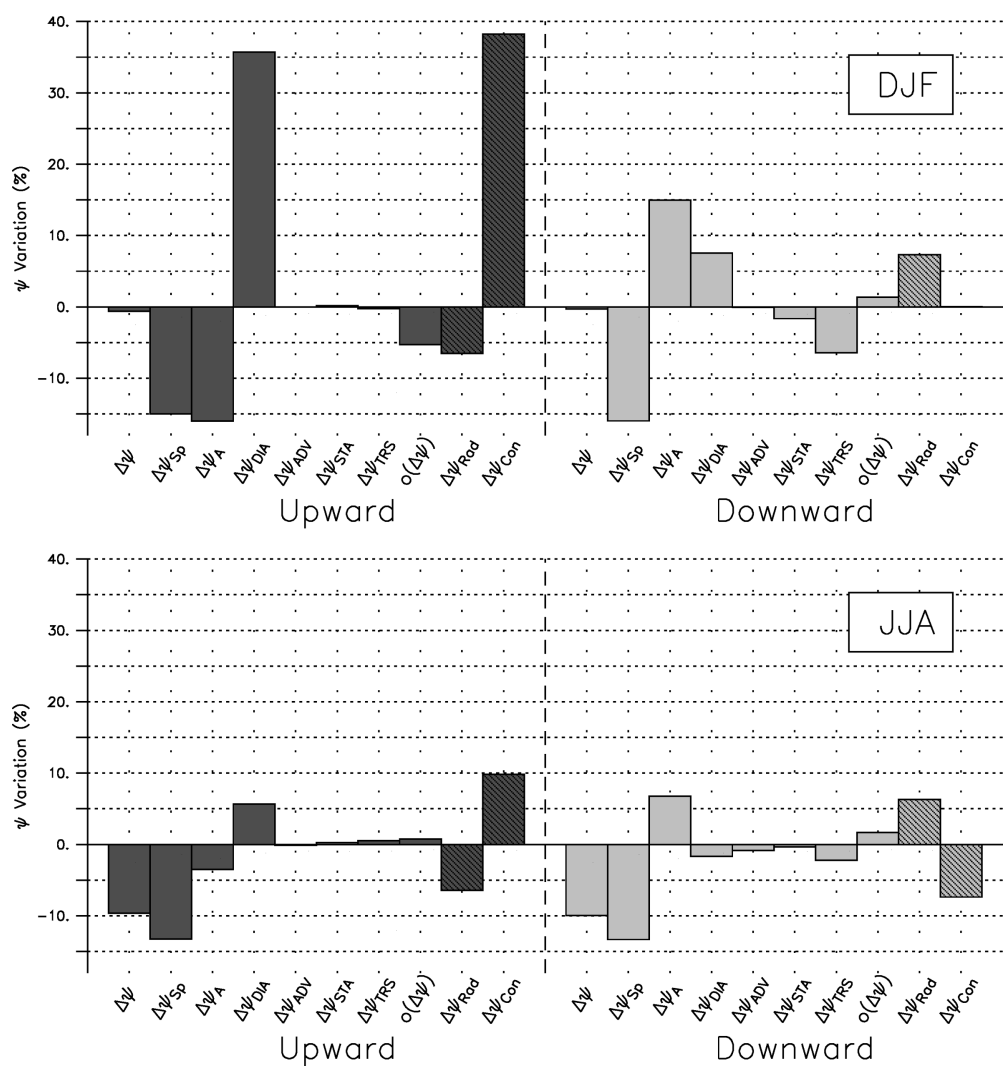

changes, as the convection is in quasi-equilibrium with its environment (Emanuel et al., 1994). The latent heating varies to adjust to mass circulation changes induced in the subsiding branch. For DJF, as the mass flux in the subsiding branch is unchanged, the latent heat flux needs to increase balance the effects of the dry static stability and area change.

During JJA, stronger latent heating is found in the subsiding branch. The stronger latent heating in the descending branch of the Hadley cell seems contradictory with the well-known tendency of the GCM to produce dryer subtropical region under global warming, following the pattern of the AR4 coupled models discussed by Held and Soden (2006). But the descending branches of the Hadley cell are defined by a zonal average and also include some part of the ITCZ, as for instance, the monsoon regions. In JJA, the stronger precipitation in the parts of ITCZ included in the subsiding branch, increases more in amplitude than the decrease of rainfall in subtropics on the other parts of the descending branch. During JJA and in the subsiding branch, the latent heating is responsible for a strong weakening of the Hadley cell.

Furthermore, in the subsiding branches, the heat flux convergence within stationary waves, and the transient eddies are weaker in the global warming simulation. The decrease of the poleward heat flux was noted in the equilibrium climate response of increasing greenhouse gases concentration in the AR4 cou- pled models by Held and Soden (2006). In the global warming simulation, the water vapour of the lower levels of the atmosphere strongly increases, following Clausius-Clapeyron equation, assuming the relative humidity constant during global warming. The strong increase of the poleward latent heat flux needed to be compensated by a decrease in the dry energy flux and, in particular, in the heat flux (Held and Soden, 2006). This weakening of the heat transport corresponds to a weakening of the Hadley cell of $-8 \%$ and $-4 \%$, for DJF and JJA, respectively.

Finally, we check the validity of our diagnostics by the residual term $o(\Delta \psi)$ in Fig. 12, which corresponds to the last term of the right-hand side of eq. (10). This term is a measure of the errors due (1) to deviations of the static stability from a uniform value in the winter Hadley cell or (2) to errors in the linearization of the changes. Except for DJF in the ascending branch, the residual is smaller than $2 \%$; therefore, our diagnostic method is well valid. And the residual term is always weak compared with the other terms. For the ascending branch during DJF, the linearization is less accurate as the diabatic changes are no longer small, which results in a rather strong residual $(6 \%)$.

\section{Discussion and conclusion}

We have analysed 18 atmosphere-ocean coupled GCMs participating to the IPCC-AR4 and studied the variation of the 
tropical Hadley circulation when the greenhouse gases concentration increases in the atmosphere. The numerical experiments used in our paper correspond to $\mathrm{CO}_{2}$ doubling simulations, part of CMIP3. The $\mathrm{CO}_{2}$ concentration was kept at a pre-industrial level at the beginning of the simulation, then increased at an annual rate of $1 \%$ and finally remained constant when the $\mathrm{CO}_{2}-$ doubling level was reached. Our study, concentrated on the winter-hemisphere Hadley circulation, can be regarded as complementary to Mitas and Clement (2006), Lu et al. (2007) and Vecchi and Soden (2007) because of our stronger emphasis on a precise quantification of the processes involving different indicators of the Hadley cell strength and limits and because they had used different simulations, either the historical simulations 20CM3 or the IPCC-scenario runs.

As a first conclusion, our results are consistent with these previous works. They show: (1) a weakening of the Hadley circulation for DJF and JJA conditions in most of the GCMs; (2) a poleward shift of the poleward limit of the Hadley cells and (3) an equatorward shift of the boundary between the Northern and Southern Hemisphere Hadley cells. We also test the significance of the changes, and the dispersion between the individual models brings large uncertainties to the estimation of the Hadley cell variations. Nevertheless, we diagnose that the changes are systematic, in particular for the Southern Hemisphere winter cell (JJA). No significant differences are found between the transient climate response and the stabilized climate response, $40 \mathrm{yr}$ after the $\mathrm{CO}_{2}$ atmospheric concentration has been stabilized.

To understand the physical processes involved in the variation of the Hadley circulation, we have performed more quantitative diagnostics with the particular IPSL-CM4 AOGCM, based on the momentum and temperature budgets. IPSL-CM4 was first compared with the other IPCC AR4 models. IPSL-CM4 shows results consistent with the other coupled model for the JJA season. On the other hand, for the DJF season, IPSL-CM4 does not give any significant changes in terms of Hadley cell position or strength.

In the model IPSL-CM4, the poleward shift of the JJA winter cell is forced by a shift in momentum convergence within transient eddies. The poleward shift of the transient eddy forcing is related to the change in the baroclinicity of the atmosphere. In case of global warming, Yin (2005) showed that the baroclinicity changes of the AR4 coupled models can be decomposed in (1) changes induced by dry static stability increase and (2) changes induced by meridional SST gradients. The response of the Southern Hemisphere Hadley cell of IPSL-CM4 seems to be coherent with the mechanism of Lu et al. (2007), where the dry static stability increase pushes the region of high baroclinicity polewards.

Nevertheless, for Northern Hemisphere winter (DJF), IPSLCM4 does not show any poleward shift of the winter Hadley cell, and the transient eddy and stationary wave forcings are unchanged. The reasons explaining the asymmetry between the Northern and the Southern Hemisphere changes are not entirely clear. In particular, the meridional SST gradient of IPSL-CM4, in the Northern Hemisphere, strongly increases during global warming as a consequence of the decreased thermohaline circulation, which induces a weak warming in the Northern Atlantic Ocean. We suggest that, in IPSL-CM4, the changes of the atmosphere baroclinicity induced by the stronger meridional SST gradient may overcome the changes induced by dry static stability. More work is needed to understand the changes in the baroclinicity of the atmosphere and the asymmetry of the changes between the two hemispheres.

The question remains as to whether the transient eddy changes are a consequence of the surface SST or the cause. Previous studies (Chen and Held, 2007; Chen and Zurita-Gotor, 2008) suggest that the increase of the eastward phase speed in the upper troposphere eddies can explain the shift of the eddy momentum convergence during global warming. Therefore, we believe that part of the poleward shift of the Hadley cells, is forced in the atmosphere by a change in the transient eddies, whose momentum convergence shifts poleward.

The separation of the different processes acting on the Hadley circulation provides nice diagnostics to test in details the processes acting on the Hadley cell. The changes in the strength of the Hadley cell in IPSL-CM4 are adequately explained by the thermodynamical changes in the atmosphere. For JJA, the weakening of the tropical circulation is explained by the dry static stability changes in the subsiding branch of the Hadley cell, whereas the diabatic heating acts to decrease this weakening by stronger radiative cooling. This mechanism is well known in models Knutson and Manabe (1995) and Sugi et al. (2002) and seems to be a robust consequence of global warming on the large-scale tropical circulation. The Hadley circulation was shown to be less affected by climate change than the longitudinal circulation such as the Walker circulation (Held and Soden, 2006; Vecchi and Soden, 2007). The processes that may explain this unexpected small weakening of the Hadley cells in IPSL-CM4 are demonstrated to involve in the relative area of the ascending and subsiding zones and the spatial occurrence of convection. The changes in the areas of the two branches of the tropical circulation were shown to have an effect on the global circulation intensity in simple box representation of the tropics (Pierrehumbert, 1995; Larson et al., 1999; Bellon et al., 2003), and our study is a first step to confirm these mechanisms in GCMs.

The anomalous Hadley circulation changes for DJF in IPSLCM4, corresponds to a very strong widening of the descending branch relative to the ascending branch, which overcomes the effect of dry static stability in the subsiding branch of the Hadley cell. As the ascending branch is narrower, the latent heating strongly increases to adjust the overturning mass circulation. If we assume that the convection and the latent heating are in quasi-equilibrium, these changes may reflect different changes in the surface properties between the Northern and Southern Hemisphere. The surface properties as the SST, the surface heat 
flux or the evaporation are determined by ocean-atmosphere coupling in coupled models. This coupling could be responsible for the different changes in the surface condition during DJF and JJA. However, the changes diagnosed for DJF are strongly model-dependent, and we have shown that IPSL-CM4 does not represent the changes of the other AR4 models for that season.

The Hadley circulation is one of the major structures of the large-scale atmospheric circulation. We showed that the Hadley circulation results from a subtle equilibrium among radiative cooling, convective heating, eddy transport and surface conditions. In GCMs and in observations, more progress is still needed to quantify the relative contributions of these processes to improve the Hadley cell representations in climate models and understand their variations in the future climate conditions.

\section{Acknowledgments}

We acknowledge the modelling groups, the Program for Climate Model Diagnosis and Intercomparaison (PCMDI) and the WCRP's Working Group on Coupled Modelling (WGCM) for their roles in making available the WCRP CMIP3 multimodel data set. Support of this data set is provided by the Office of Science, U.S. Department of Energy. We also thank B. J. Soden and two anonymous reviewers, who contributed to improve this paper, for their suggestions and comments.

\section{Appendix A: The Hadley change of the AR4 AOGCM}

The changes among the 14 AR4 coupled GCMs used for the results of Fig. 1 are given to illustrate the spread of the climate
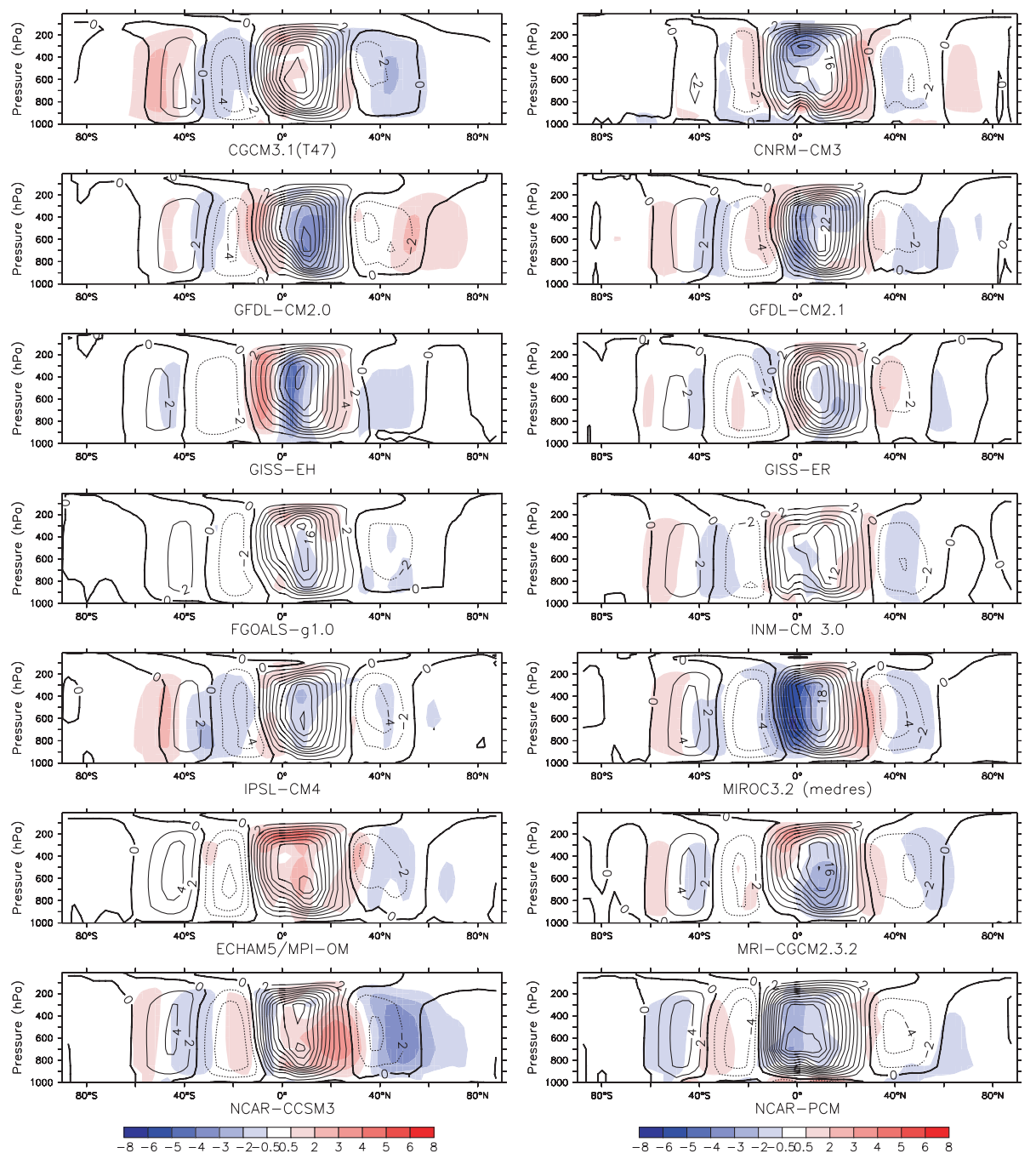

Fig. 13. Mean Meridional streamfunction $\left(10^{10} \mathrm{~kg} \mathrm{~s}^{-1}\right)$ during DJF, for the pre-industrial control simulation (1CO $)$ in contour. Contour interval is $2 \times 10^{10} \mathrm{~kg} \mathrm{~s}^{-1}$. The differences between the $2 \mathrm{CO}_{2}-\mathrm{STA}$ simulation and the $1 \mathrm{CO}_{2}$ simulation are displayed in colour. The colour scale is shown at the bottom. The 14 models shown correspond to those used for the multimodel ensemble mean in Fig. 1. 

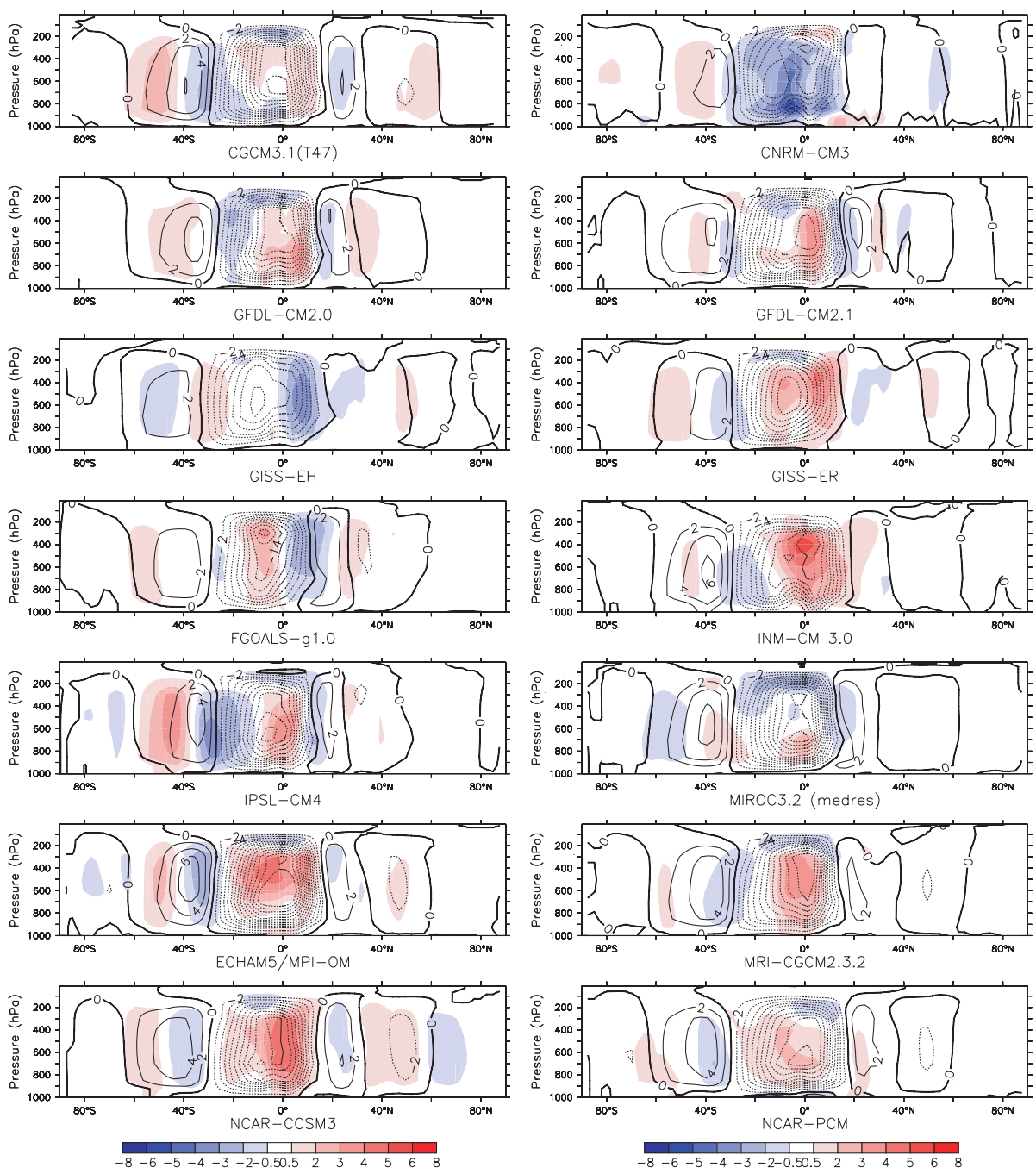

Fig. 14. Same as Fig. 13 but for JJA.

change of the Hadley circulation. Figure 13 shows the mean meridional streamfunction for the Northern Hemisphere winter (DJF). The mean meridional streamfunction of the control simulation $\left(1 \mathrm{CO}_{2}\right)$ is in contour, whereas the changes $2 \mathrm{CO}_{2}^{-}$ STA- $-1 \mathrm{CO}_{2}$ are in colour shades. Figure 14 is the same as Fig. 13 but for JJA, Southern Hemisphere winter.

We can note that the coupled GCMs display a wide range of shapes in the $1 \mathrm{CO}_{2}$ simulation streamfunction for the Hadley winter cells. For instance, the pressure level of the streamfunction maximum absolute value is poorly constrained.

The changes in the $2 \mathrm{CO}_{2}$-STA simulation, shown in colour shade, also show a wide range of response. The low level of statistical significance of the Hadley cells weakening is a consequence of the strong dispersion of the climate changes responses.

\section{Appendix B: Time-series of Hadley circulation strength among the AR4 coupled GCM}

The time-series of the maximum (DJF) and minimum (JJA) of the mean meridional streamfunction are computed among the 18 models analysed. Figures 15 and 16 show the time-series for DJF and JJA, in the $1 \mathrm{CO}_{2}$ and $2 \mathrm{CO}_{2}$ simulations, respectively. The linear trend is shown in dashed line.

Most of the models show a weakening of the mean meridional circulation, for DJF and JJA, in the period of the $\mathrm{CO} 2$ increase in the atmosphere. In contrast, the pre-industrial control simulation $\left(1 \mathrm{CO}_{2}\right)$ does not show any trend.

The values of the trends and their significances correspond to the values given in Table 1 . 

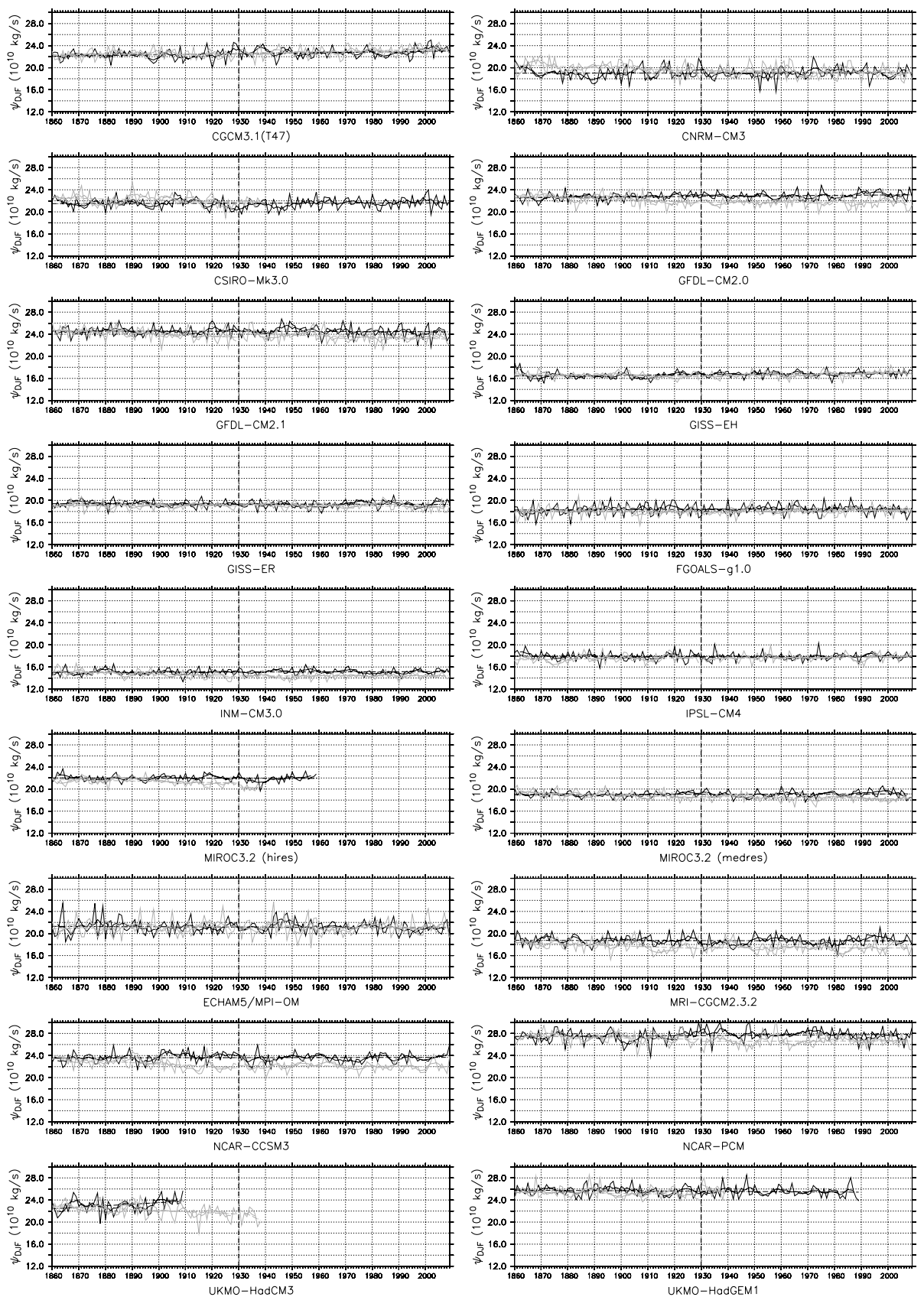

Fig. 15. Time-series of the maximum value of the mean meridional streamfunction among the AR4 models, for DJF. The two black curves indicate the value for the pre-industrial control simulation $\left(\mathrm{CO}_{2}\right)$, first without any smoothing, and then smoothed with a 5 -yr running mean. The dashed black curve show the linear regression curve. The grey curve indicates the same curves but for the $2 \mathrm{CO}_{2}$ simulation. The thick dashed vertical line indicated the time of the stabilization of the $\mathrm{CO}_{2}$ concentration. The time axis is arbitrary chosen for a beginning of the simulation at the year 1860 .

\section{Appendix C: The effect of the thermodynamic changes on the Hadley cell strength}

We derive the Hadley cell strength from eq. (3) by an integral of the vertical velocities over the area covered by the ascending and subsiding branches of the Hadley cells.
The area covered by the Hadley cells, is defined by the mean meridional streamfunction using the vertical velocity. The mean meridional streamfunction is computed using

$\psi=\int_{-\pi}^{\phi} \frac{2 \pi a^{2}}{g}\langle\bar{\omega}\rangle \cos \phi \mathrm{d} \phi$ 

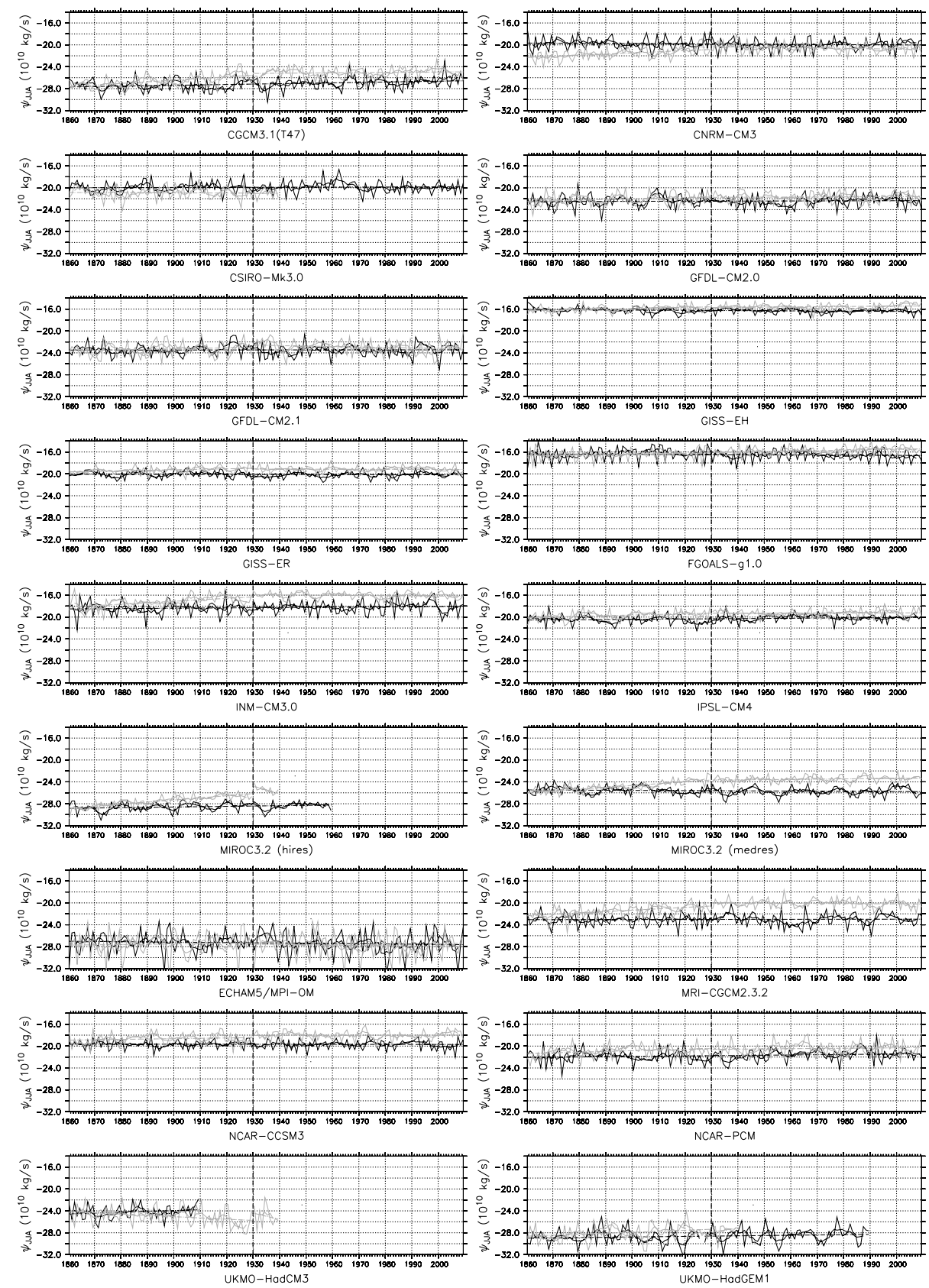

Fig. 16. Same as Fig. 15 for JJA.

The position of the winter Hadley cell is given by the latitudes where the streamfunction is zero, found with horizontal interpolation, at the $500 \mathrm{hPa}$ height. We find the limits $\lambda_{\mathrm{N}}$ and $\lambda_{\mathrm{Eq}}$ for the equatorward and the poleward limits of the winter Hadley cell for DJF. In the case of DJF, the latitude $\lambda_{\max }$, where the streamfunction is maximum, is computed to delimit the ascending and the subsiding branches within the winter Hadley cell. Figure 17 gives an illustration of the Hadley cell geometry for DJF.
Likewise, we can find the position of the winter Hadley cell for JJA with the latitudes $\lambda_{\mathrm{S}}, \lambda_{\mathrm{Eq}}$ and $\lambda_{\min }$.

For DJF, one can find the Hadley cell strength with integration over the subsiding branch:

$\max (|\psi|)=\int_{\lambda_{N}}^{\lambda_{\max }} \frac{2 \pi a^{2}}{g}\langle\bar{\omega}\rangle \cos \phi \mathrm{d} \phi$,

Or, with integration over the ascending branch:

$\max (|\psi|)=\int_{\lambda_{\max }}^{\lambda_{\mathrm{Eq}}} \frac{2 \pi a^{2}}{g}\langle\bar{\omega}\rangle \cos \phi \mathrm{d} \phi$. 


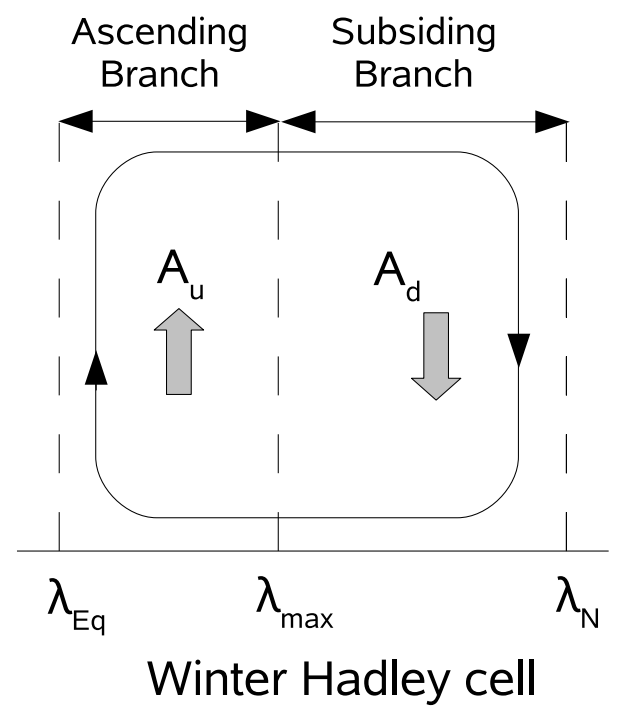

Fig. 17. Description of the DJF Hadley cell, and separation between the ascending and the subsiding branches. The areas covered by the ascending and descending branches are noted $A_{u}$ and $A_{d}$.

In the following, for simplicity, our methodology is illustrated only to the DJF winter Hadley cell subsiding branch.

First, we substitute the value of the zonal mean vertical pressure velocity of eq. (3),

$$
\begin{aligned}
\max (|\psi|) & =\int_{\lambda_{N}}^{\lambda_{\max }} \frac{2 \pi a^{2}}{g}\langle\bar{\omega}\rangle \cos \phi \mathrm{d} \phi \\
& =\int_{\lambda_{N}}^{\lambda_{\max }} \frac{1}{S_{p}} \frac{2 \pi a^{2}}{g}\left(\left\langle\delta T_{\mathrm{ADV}}\right\rangle+\left\langle\delta T_{\mathrm{STA}}\right\rangle\right. \\
& \left.+\left\langle\delta T_{\mathrm{TRS}}\right\rangle+\left\langle\delta T_{\mathrm{DIA}}\right\rangle\right) \cos \phi \mathrm{d} \phi .
\end{aligned}
$$

At the first order, $S_{p}$ is uniform and equal to $\left.S_{p}\right|_{d}$ in the descending branch. The vertical bar followed by a subscript $d$ indicates the average over the descending branch of the winter cell, defined between $\lambda_{\mathrm{N}}$ and $\lambda_{\max }$.

$$
\begin{aligned}
\max (|\psi|) & =\frac{1}{\left.S_{p}\right|_{d}}\left(\int_{\lambda_{N}}^{\lambda_{\max }} \frac{2 \pi a^{2}}{g}\left\langle\delta T_{\mathrm{ADV}}\right\rangle \cos \phi \mathrm{d} \phi\right. \\
& +\int_{\lambda_{N}}^{\lambda_{\max }} \frac{2 \pi a^{2}}{g}\left\langle\delta T_{\mathrm{STA}}\right\rangle \cos \phi \mathrm{d} \phi \\
& +\int_{\lambda_{N}}^{\lambda_{\max }} \frac{2 \pi a^{2}}{g}\left\langle\delta T_{\mathrm{TRS}}\right\rangle \cos \phi \mathrm{d} \phi \\
& \left.+\int_{\lambda_{N}}^{\lambda_{\max }} \frac{2 \pi a^{2}}{g}\left\langle\delta T_{\mathrm{DIA}}\right\rangle \cos \phi \mathrm{d} \phi\right) \\
& +o(\max (|\psi|)) .
\end{aligned}
$$

Here, the small term $o(\max (|\psi|))$ is a consequence of deviation of $S_{p}$ from a uniform value equal to $\left.S_{p}\right|_{d}$. We can show that the hypothesis of a uniform dry static stability in the Hadley circulation region is reasonable.
Then,

$$
\begin{aligned}
\max (|\psi|) & =\frac{\left.\left\langle\delta T_{\mathrm{ADV}}\right\rangle\right|_{d} A_{d}}{\left.S_{p}\right|_{d}}+\frac{\left.\left\langle\delta T_{\mathrm{STA}}\right\rangle\right|_{d} A_{d}}{\left.S_{p}\right|_{d}} \\
& +\frac{\left.\left\langle\delta T_{\mathrm{TRS}}\right\rangle\right|_{d} A_{d}}{\left.S_{p}\right|_{d}}+\frac{\left.\left\langle\delta T_{\mathrm{DIA}}\right\rangle\right|_{d} A_{d}}{\left.S_{p}\right|_{d}} \\
& +o(\max (|\psi|)) .
\end{aligned}
$$

Here, $A_{d}$ is the area of the subsiding branch computed as

$A_{d}=\int_{\lambda_{N}}^{\lambda_{\max }} \frac{2 \pi a^{2}}{g} \cos \phi \mathrm{d} \phi$.

Then, we linearize eq. (C6); as long as the changes of each term of eq. (C6) are small, we can write the change in the Hadley circulation strength as a result of each change in the atmosphere:

$$
\begin{aligned}
& \frac{\Delta \max (|\psi|)}{\max (|\psi|)}=\frac{\Delta A_{d}}{A_{d}}-\frac{\left.\Delta S_{p}\right|_{d}}{\left.S_{p}\right|_{d}} \\
& +\frac{\left.\Delta\left\langle\delta T_{\mathrm{ADV}}\right\rangle\right|_{d}+\left.\Delta\left\langle\delta T_{\mathrm{STA}}\right\rangle\right|_{d}+\left.\Delta\left\langle\delta T_{\mathrm{TRS}}\right\rangle\right|_{d}+\left.\Delta\left\langle\delta T_{\mathrm{DIA}}\right\rangle\right|_{d}}{\left.\left\langle\delta T_{\mathrm{ADV}}\right\rangle\right|_{d}+\left.\left\langle\delta T_{\mathrm{STA}}\right\rangle\right|_{d}+\left.\left\langle\delta T_{\mathrm{TRS}}\right\rangle\right|_{d}+\left.\left\langle\delta T_{\mathrm{DIA}}\right\rangle\right|_{d}} \\
& \quad+o\left(\frac{\Delta \max (|\psi|)}{\max (|\psi|)}\right)
\end{aligned}
$$

Similar computation is performed for the DJF winter Hadley cell ascending branch, using a vertical bar followed by a subscript $u$ to indicate averaged values over the ascending branch. The asending branch is defined between $\lambda_{\mathrm{Eq}}$ and $\lambda_{\max }$. The computation is also performed for the JJA winter Hadley cell ascending (between $\lambda_{\mathrm{Eq}}$ and $\lambda_{\text {min }}$ ) and subsiding (between $\lambda_{\min }$ and $\lambda_{S}$ ) branches.

\section{References}

Bellon, G., Treut, H. L. and Ghil, M. 2003. Large-scale and evaporationwind feedbacks in a box model of the tropical climate. Geophs. Res. Lett. 30, 2145-2150.

Betts, A. K. and Ridgway, W. 1988. Coupling of the radiative, convective, and surface fluxes over the equatorial pacific. J. Atmos. Sci. 45, 522-536.

Bony, S. and Emanuel, K. 2001. A parametrization of cloudiness associated with cumulus convection; evaluation using TOGA COARE data. J. Atmos. Sci. 58, 3158-3183.

Chen, G. and Held, I. M. 2007. Phase speed spectra and recent poleward shift of Southern Hemisphere surface westerlies. Geophys. Res. Lett. 34, L21805, doi:10.1029/2007GL031200.

Chen, G. and Zurita-Gotor, P. 2008. The tropospheric jet response to prescribed zonal forcing in an idealized atmospheric model. J. Atmos. Sci. 65, 2254-2271.

Clement, A. C. and Soden, B. 2005. The sensitivity of the tropical-mean radiation budget. J. Clim. 18, 3189-3204.

Emanuel, K. A. 1993. A cumulus representation based on the episodic mixing model: the importance of mixing and microphysics in predicting humidity. AMS Meterol. Monogr. 24, 185-192.

Emanuel, K. A., Neelin, J. D. and Bretherton, C. S. 1994. On large-scale circulations in convecting atmospheres. Q. J. R. Meteorol. Soc. 120, $1111-1143$. 
Fu, Q., Johanson, C., Wallace, J. and Reichler, T. 2006. Enhanced midlatitude tropospheric warming in satellite measurements. Science 312, 1179 .

Held, I. M. and Soden, B. J. 2006. Robust responses of the hydrological cycle to global warming. J. Clim. 19, 5686-5699.

Hourdin, F., Musat, I., Bony, S., Braconnot, P., Codron, F. and coauthors. 2006. The LMDZ4 general circulation model: climate performance and sensitivity to parametrized physics with emphasis on tropical convection. Clim. Dyn. 27, 787-813.

$\mathrm{Hu}$, Y. and Fu, Q. 2007. Observed poleward expansion of the hadley circulation since 1979. Atmos. Chem. Phys. 7, 52295236.

Knutson, T. and Manabe, S. 1995. Time mean response over the tropical pacific to increased $\mathrm{CO}_{2}$ in a coupled ocean-atmosphere model. $J$. Clim. 8, 2181-2199.

Larson, K., Hartmann, D. L. and Klein, S. A. 1999. The role of clouds, water vapor, circulation, and boundary layer structure in the sensitivity of the tropical climate. J. Clim. 12, 2359-2374.

$\mathrm{Li}, \mathrm{Z} .2006$. Atmospheric GCM response to an idealized anomaly of the Mediterranean sea surface temperature. Clim. Dyn. 27, 543-552.

Lu, J., Vecchi, G. A. and Reichler, T. 2007. Expansion of the Hadley cell under global warming. Geophys. Res. Lett. 34, L06805, doi:10.1029/2006GL028443.

Mitas, C. M. and Clement, A. 2005. Has the Hadley cell been strengthening in recent decades? Geophys. Res. Lett. 32, L01810, doi:10.1029/2005GL024406.

Mitas, C. M. and Clement, A. 2006. Recent behavior of the Hadley cell and tropical thermodynamics in climate models and reanalyses. Geophys. Res. Lett. 33, L01810, doi:10.1029/2005GL024406.

Oort, A. and Yienger, J. 1996. Observed interannual variability in the hadley circulation and its connection to ENSO. J. Clim. 9, 2751-2767.
Peixoto, J. P. and Oort, A. H. 1982. Physics of Climate. Springer, New York, US .

Pierrehumbert, R. T. 1995. Thermostats, radiators fins, and the local runaway greenhouse. J. Atmos. Sci. 52, 1784-1806.

Santer, B. D., Widgey, T. M. L., Boyle, J. S., Gaffen, D. J., Hnilo, J. J. and co-authors. 2000. Statistical significance of trends and trend differences in layer-avergae temperature time series. J. Geophys. Res. 105, 7337-7356.

Santer, B. D., Sausen, R., Wigley, T. M., Boyle, J. S., AchutaRao, K. and co-authors. 2003. Behavior of tropopause height and atmospheric temperature in models, reanalyses, and observations: decadal changes. J. Geophys. Res. 108, 4002, doi:10.1029/2002JD002258.

Seager, R., Harnik, N., Kushnir, Y., Robinson, W. and Miller, J. 2003. Mechanisms of hemispherically symmetric climate variability. $J$. Clim. 16, 2960-2978.

Sugi, M., Noda, A. and Sato, N. 2002. Influence of the global warming on tropical cyclone climatology: an experiment with the JMA global model. J. Meteor. Soc. Japan 80, 249-272.

Vecchi, G. and Soden, B. 2007. Global warming and the weakening of the tropical circulation. J. Clim. 20, 4316-4340.

Vecchi, G. A., Soden, B. J., Wittenberg, A. T., Held, I. M., Leetmaa, A. and co-authors. 2006. Weakening of the tropical atmospheric circulation due to antropogenic forcing. Nature 441, 73-76.

Waliser, D. E., Shi, Z., Lanzante, J. R. and Oort, A. H. 1999. The Hadley circulation: assessing NCEP/NCAR reanalysis and sparse insitu estimates. Clim. Dyn. 15, 719-735.

$\mathrm{Xu}$, K.-M. and Emanuel, K. 1989. Is the atmosphere conditionally unstable? Mon. Wea. Rev. 117, 1471-1479.

Yin, J. H. 2005. A consistent poleward shift of the storm tracks in the simulations of 21 st century climate. Geophys. Res. Lett. 32, L18701, doi:10.1029/2005GL023684. 